\title{
Near-Real-Time Surface-Based CAPE from Merged Hyperspectral IR Satellite Sounder and Surface Meteorological Station Data
}

\author{
CALlyn Bloch AND Robert O. KNUTESON \\ Cooperative Institute for Meteorological Satellite Studies, Space Science and Engineering Center, University of \\ Wisconsin-Madison, Madison, Wisconsin \\ ANTONia GAmbacorta AND NichOlas R. NALLI \\ I.M. Systems Group, Inc., Rockville, and NOAA/NESDIS/Center for Satellite Applications and Research, \\ College Park, Maryland \\ JESSICA GARTZKE \\ Cooperative Institute for Meteorological Satellite Studies, Space Science and Engineering Center, University of \\ Wisconsin-Madison, Madison, Wisconsin \\ LIHANG ZHOU \\ NOAA/NESDIS/Center for Satellite Applications and Research, College Park, Maryland
}

(Manuscript received 6 June 2018, in final form 9 May 2019)

\begin{abstract}
Near-real-time satellite-derived temperature and moisture soundings provide information about the changing atmospheric vertical thermodynamic structure occurring between successive routine National Weather Service (NWS) radiosonde launches. In particular, polar-orbiting satellite soundings become critical to the computation of stability indices over the central United States in the midafternoon, when there are no operational NWS radiosonde launches. Accurate measurements of surface temperature and dewpoint temperature are key in the calculation of severe weather indices, including surface-based convective available potential energy (SBCAPE). This paper addresses a shortcoming of current operational infrared-based satellite soundings, which underestimate the surface parcel temperature and dewpoint when CAPE is nonzero. This leads to a systematic underestimate of SBCAPE. This paper demonstrates a merging of satellite-derived vertical profiles with surface observations to address this deficiency for near-real-time applications. The National Oceanic and Atmospheric Administration (NOAA) Center for Environmental Prediction (NCEP) Meteorological Assimilation Data Ingest System (MADIS) hourly surface observation data are blended with satellite soundings derived using the NOAA Unique Combined Atmospheric Processing System (NUCAPS) to create a greatly improved SBCAPE calculation. This study is not intended to validate NUCAPS or the combined NUCAPS + MADIS product, but to demonstrate the benefits of combining observational weather satellite profile data and surface observations. Two case studies, 18 June 2017 and 3 July 2017, are used in this study to illustrate the success of the combined NUCAPS + MADIS SBCAPE compared to the NUCAPS-only SBCAPE estimate. In addition, a 6-month period, April-September 2018, was analyzed to provide a comprehensive analysis of the impact of using surface observations in satellite SBCAPE calculations. To address the need for reduced data latency, a near-real-time merged satellite and surface observation product is demonstrated using NUCAPS products from the Community Satellite Processing Package (CSPP) applied to direct broadcast data received at the University of Wisconsin-Madison, Hampton University in Virginia, and the Naval Research Laboratory in Monterey, California. Through this study, it is found that the combination of the MADIS surface observation data and the NUCAPS satellite profile data improves the SBCAPE estimate relative to comparisons with the Storm Prediction Center (SPC) mesoscale analysis and the NAM analysis compared to the NUCAPS-only SBCAPE estimate. An assessment of the 6-month period between April and September 2018 determined the dry bias in NUCAPS at the surface is the primary cause of the underestimation of the NUCAPS-only SBCAPE estimate.
\end{abstract}

Corresponding author: Callyn Bloch, cebloch@wisc.edu 


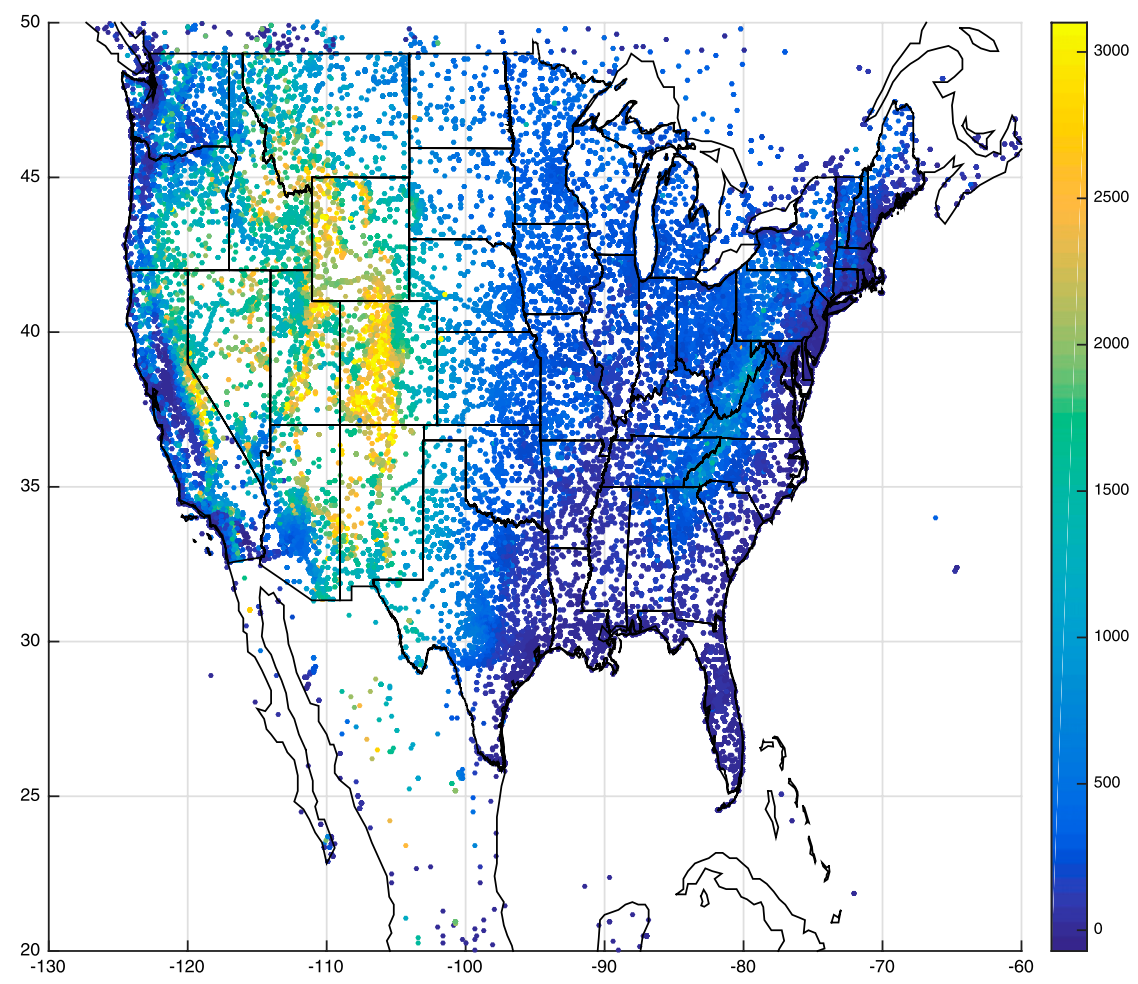

FIG. 1. High-density MADIS station locations. The color of the dot represents station elevation $(\mathrm{m})$.

\section{Introduction}

The timely issuance of severe weather watches and warnings is important for public safety; however, the accurate prediction of severe weather has many observational and modeling challenges (McNulty 1995; Cintineo et al. 2014; Johns and Doswell 1992). Nearreal-time satellite observations can provide forecasters the supplemental knowledge they need to issue these timely and accurate watches and warnings (Rothfusz et al. 2014; Smith et al. 2009). The convective available potential energy (CAPE) is a well-established measure of buoyancy-driven atmospheric instability that is computed from vertical profiles of temperature and water vapor (Blanchard 1998; Doswell and Rasmussen 1994; Holley et al. 2014). CAPE is important in forecasting severe weather, and is also used to derive other severe weather parameters including the bulk Richardson number (BRN), the significant tornado parameter (STP), and the supercell composite parameter (SCP). (Bunkers et al. 2002; Riemann-Campe et al. 2009). The following equation defines CAPE (Blanchard 1998):

$$
\mathrm{CAPE}=g \int_{\mathrm{LFC}}^{\mathrm{EL}} \frac{\left(T_{v, \text { parcel }}-T_{v, \mathrm{env}}\right)}{T_{v, \mathrm{env}}} d z
$$

where the bounds of the integral are the equilibrium level (EL) and the level of free convection (LFC), respectively. The virtual temperature of the parcel is $T_{v \text {,parcel, and }}$ $T_{v \text {,env }}$ is the virtual temperature of the environment. The virtual parcel is used to calculate CAPE since it includes the effects of moisture on density via the virtual temperature. There are many variations in the selection of the parcel to be lifted in the computation (Doswell and Rasmussen 1994). The three most common parcel types are surface-based parcels (SBCAPE), mean-layer or mixed-level parcels (MLCAPE), and most unstable parcels (MUCAPE) (Rochette et al. 1999; Thompson et al. 2002; Craven et al. 2002). Craven et al. (2002) have shown that the mixed-layer parcel is best for estimating cloud base height and the lifting condensation level (LCL), however, it is noted that there is value in the use of the surface-based parcel to provide convective estimates between radiosonde site locations and launch times. This study uses the SBCAPE to provide nearly contiguous spatial coverage at satellite overpass times, which fill in the temporal sampling gaps between radiosonde launch times in the continental United States (CONUS).

There are certain thresholds for CAPE values that forecasters use to define categories for describing potential risk assessment in the mesoscale discussions 
according to the National Oceanic and Atmospheric Administration (NOAA)/National Weather Service (NWS) Storm Prediction Center (SPC). CAPE values less than $1000 \mathrm{~J} \mathrm{~kg}^{-1}$ are considered weak instability, $1000-2500 \mathrm{~J} \mathrm{~kg}^{-1}$ are moderate instability, $2500-4000 \mathrm{~J} \mathrm{~kg}^{-1}$ are strong instability, and values above $4000 \mathrm{~J} \mathrm{~kg}^{-1}$ are considered extreme instability (https://www.spc.noaa.gov/ sfctest/help/sfcoa.html). Traditionally, forecasters have relied on upper-air soundings using weather balloons for verification of numerical weather model forecasts, but these are only launched twice a day at 0000 and 1200 UTC, or 1900-1600 and 0700-0400 local standard time from eastern standard time to Pacific standard time. These launch times are inconvenient in the continental United States for identifying severe weather because they are launched well before and after maximum daytime heating when thunderstorms initiate (Gartzke et al. 2017). It should be noted that special soundings are launched during certain severe weather events, but this is not a daily occurrence. Satellite vertical sounding data from hyperspectral infrared sensors are a potential resource to determine the atmospheric conditions between radiosonde launches and between launch sites assuming low latency is provided. In particular, polarorbiting weather satellite overpasses from EUMETSAT MetOp with the Infrared Atmospheric Sounder Instrument (IASI) have a 0930 and 2130 local overpass time. The National Aeronautics and Space Administration (NASA) Aqua satellite with the Atmospheric Infrared Sounder (AIRS) instrument and the Suomi National Polar-Orbiting Partnership (SNPP) and NOAA-20 satellites with the Cross-Track Infrared Sounder (CrIS) instrument have a local overpass time of about 0130 and 1330. These overpasses occur conveniently between the operational NWS radiosondes in the continental United States (Goldberg et al. 2013). In addition to better temporal sampling, satellite sounder data can provide improved spatial coverage between NWS radiosonde launch sites with a spatial sampling of about $50 \mathrm{~km}$ instead of $250-\mathrm{km}$ spacing between NWS launch sites. The value of using polar-orbiting satellite sounding data has been recognized at the NOAA Hazardous Weather Testbed (HWT) Spring Experiments held at the NWS SPC (https://hwt.nssl.noaa.gov/) (Wheeler et al. 2018).

The NOAA Unique Combined Atmospheric Processing System (NUCAPS) was developed to provide global atmospheric vertical temperature and moisture profiles from NOAA operational weather satellites and has been extended to include EUMETSAT MetOp weather satellites (Gambacorta and Barnet 2013; Gambacorta 2013; Gambacorta et al. 2014a,b, 2015, 2017). NUCAPS products are derived from the
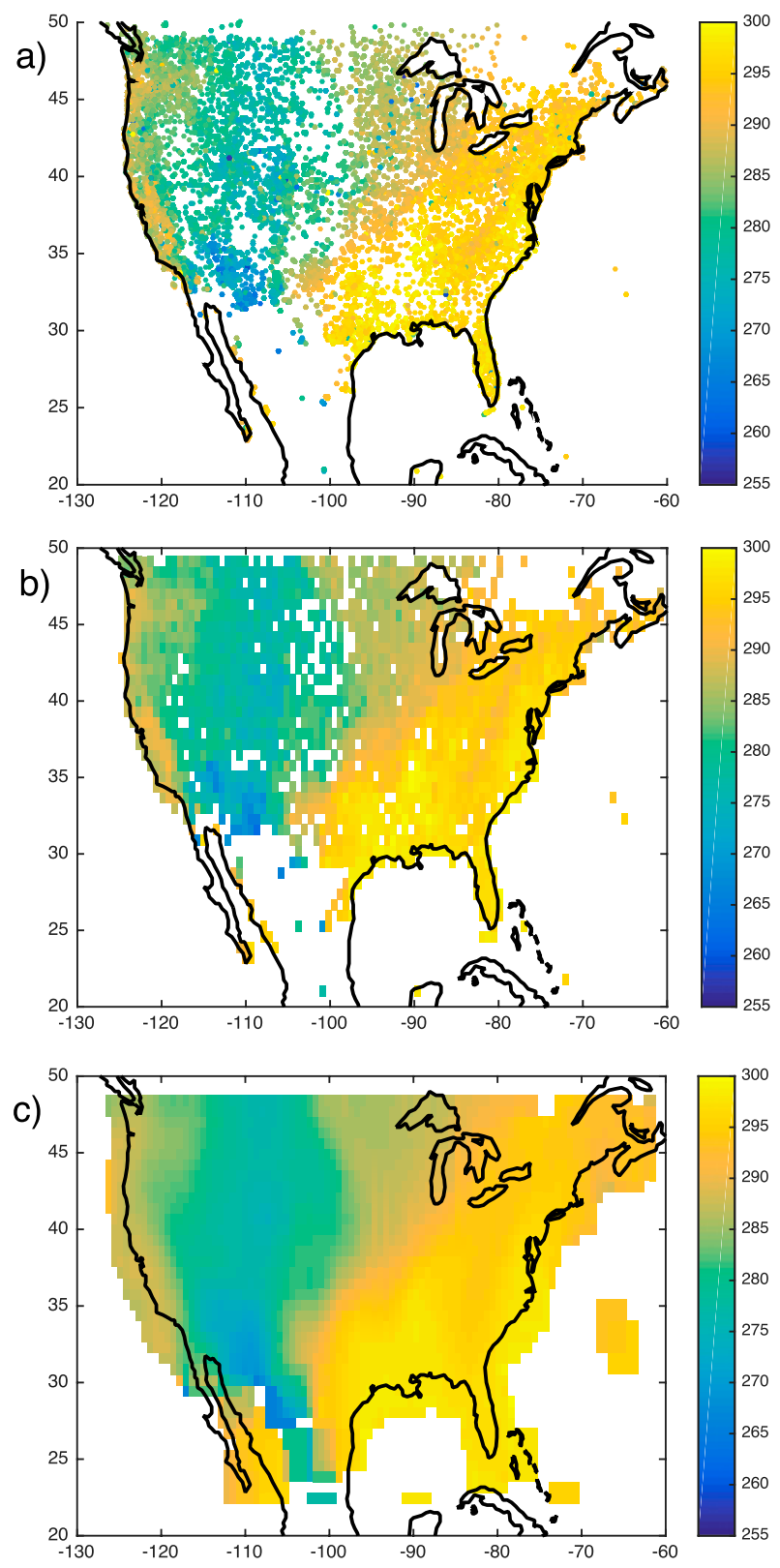

FIG. 2. Example MADIS surface dewpoint data for 1800 UTC 18 Jun 2017. (a) The individual stations with the reported surface dewpoint. (b) The station data averaged onto a $0.7^{\circ} \times 0.7^{\circ}$ grid. (c) The smoothed gridded data is achieved with a $3 \times 3$ boxcar spatial convolution.

combined use of satellite-based microwave and infrared radiance observations. NUCAPS is currently used to process the CrIS and the Advanced Technology Microwave Sounder (ATMS) suite of instruments currently onboard the NASA SNPP satellite and on $N O A A-20$ as well as the IASI, the Advanced Microwave Sounding Unit (AMSU), and the Microwave Humidity Sounder (MHS) suite of instruments on board the 
a)

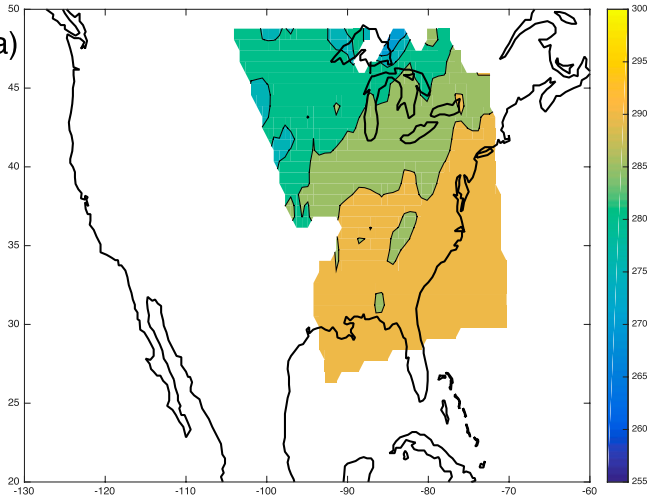

c)

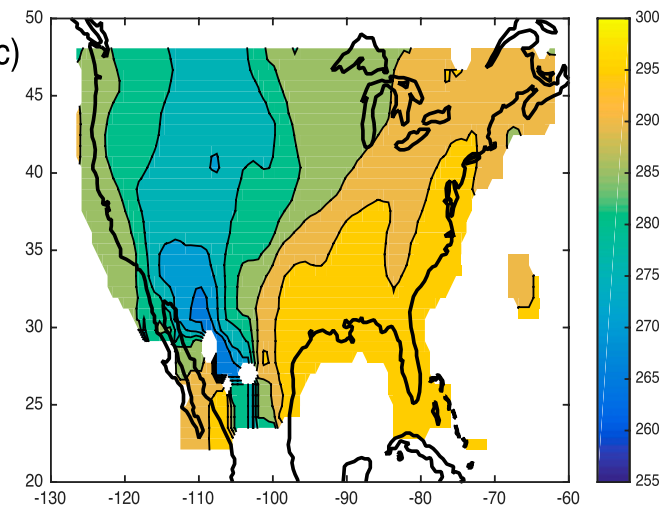

b)

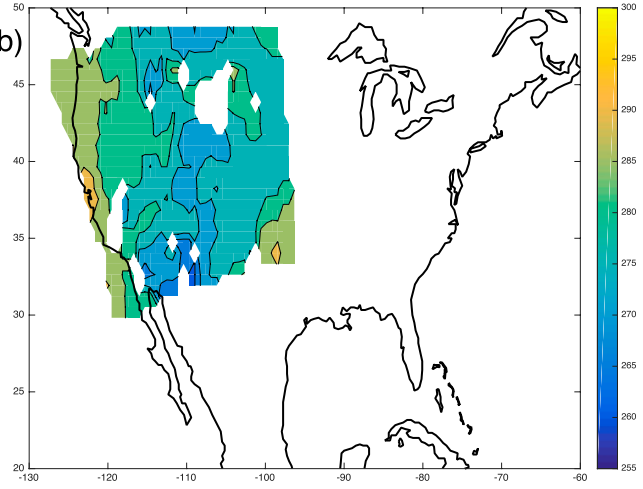

d)

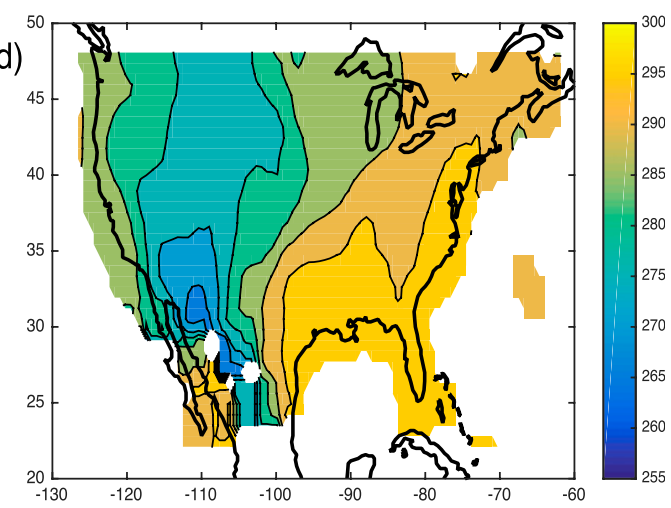

FIG. 3. (a) The eastern daytime overpass of the NUCAPS satellite surface dewpoint estimate at 1827 UTC 18 Jun 2017, which is matched with (c) the smoothed hourly contour plot of MADIS observed surface dewpoint at 1800 UTC on the same day. (b) Similarly, the subsequent overpass covering the western United States on the same day at 2009 UTC is matched with (d) the hourly MADIS data at 2000 UTC.

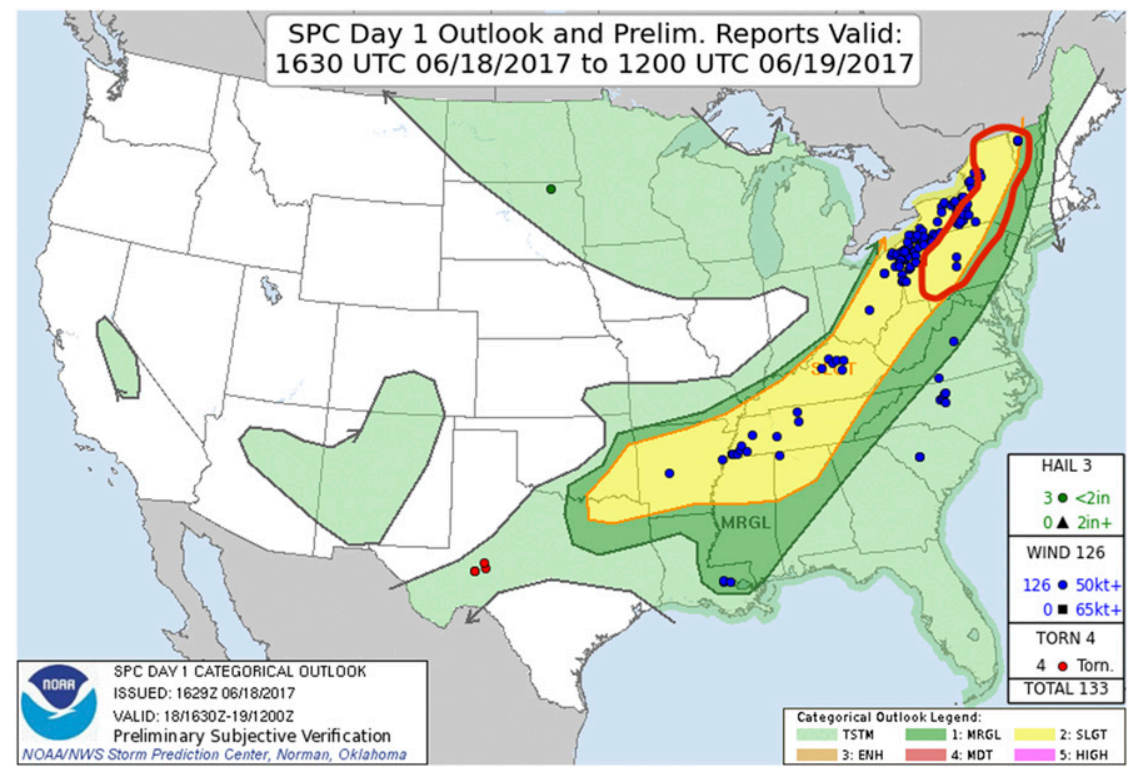

FIG. 4. SPC convective outlook for 1630 UTC 18 Jun 2017 and storm reports for the valid time (https://www.spc.noaa.gov/exper/archive/events/). The red outline depicts the region described in the SPC mesoscale discussion 1087 valid for the same day at 1900 UTC. 
a)

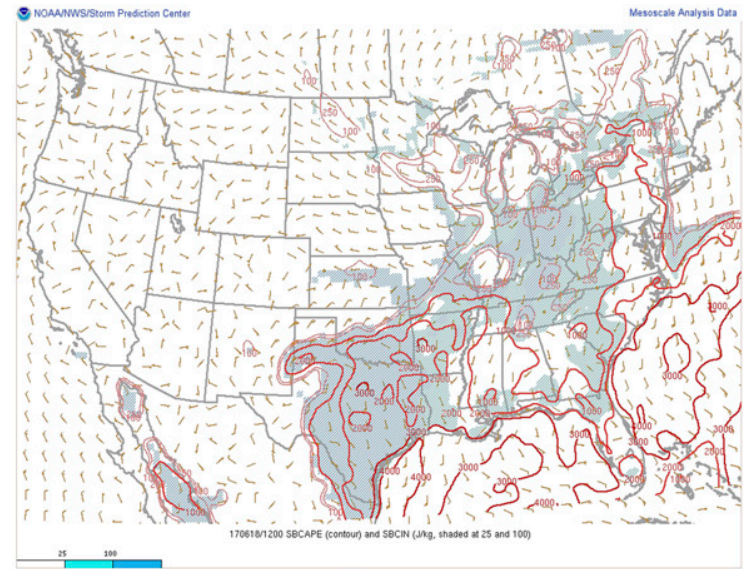

b)

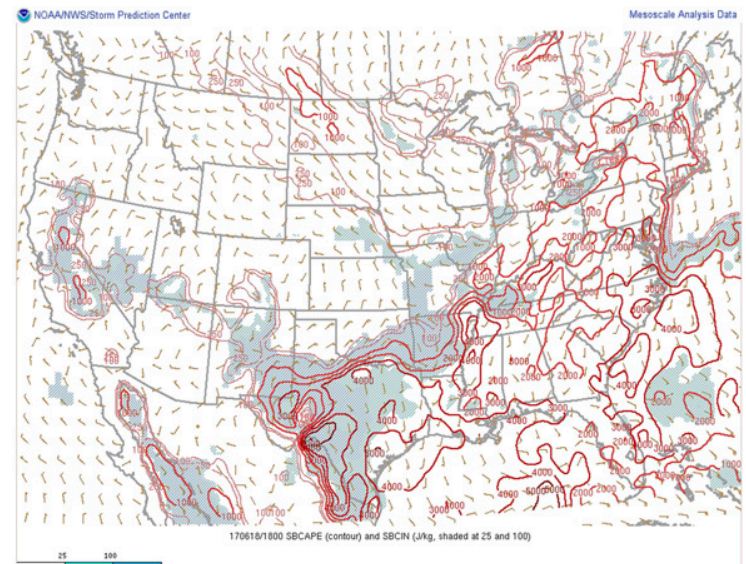

FIG. 5. SPC severe weather event archives mesoscale analysis of SBCAPE (red contours) and SBCIN (blue fill) for (a) 1200 and (b) 1800 UTC 18 Jun 2017.

MetOp satellites (Gambacorta 2013) with global products archived at NOAA Comprehensive Large Arraydata Stewardship System (CLASS). For near-real-time applications, NUCAPS has been implemented in the Community Satellite Processing Package (CSPP) for processing direct broadcast (DB) data from $S N P P$ and $N O A A-20$ that provides a product latency of less than $30 \mathrm{~min}$ (http://cimss.ssec.wisc.edu/cspp/). One of the outcomes of this study is the near-real-time visualization of polar-orbiting sounder atmospheric stability products using the Space Science and Engineering Center (SSEC) visualization tool RealEarth (https:// realearth.ssec.wisc.edu/) derived from DB CSPP NUCAPS data collected at stations in Hampton, Virginia; Madison, Wisconsin; and Monterey, California. The visualization of these products is discussed in the appendix.

NUCAPS has been running operationally since 2013 using SNPP CrIS/ATMS data. The NUCAPS global temperature and moisture profile Environmental Data Records (EDR) products have been thoroughly
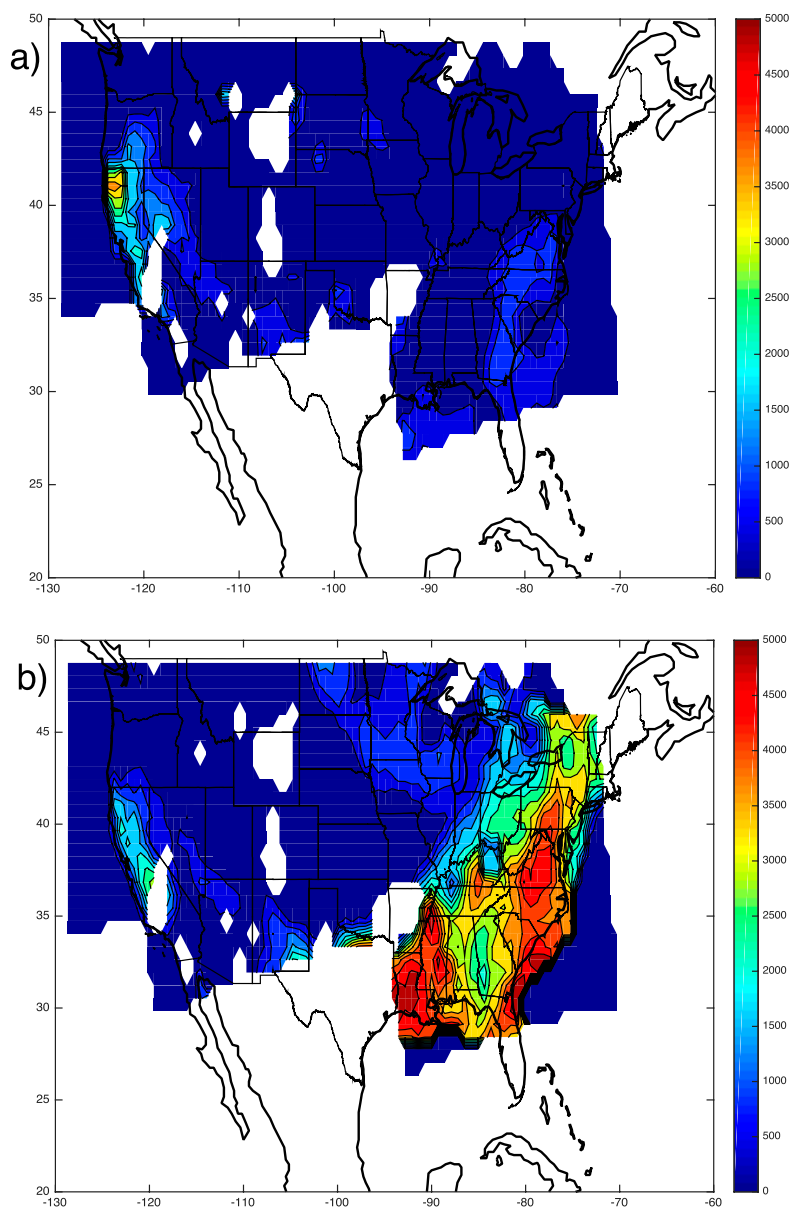

FIG. 6. (a) NUCAPS surface-based CAPE estimate without MADIS data, and (b) the same NUCAPS data for the same date and time as in (a) but combined with MADIS surface data. The images are from the afternoon overpasses on 18 Jun 2017. The overpasses displayed are from 1651 to 2151 UTC from east to west.

validated (Nalli et al. 2018; Sun et al. 2017). Stability indices derived from NUCAPS are proven to be useful in evaluating preconvective environments, which was evaluated in a study by Iturbide-Sanchez et al. (2018). However, because of the increased opacity of the boundary layer and, for land regimes, uncertainties in the surface emissivity, satellite soundings often suffer from a cold and dry bias when estimating the surface parcel (Gambacorta and Barnet 2013, 2018). The validation of both NUCAPS and AIRS, version 5, sounding profiles show an increased uncertainty in the boundary layer over land (Nalli et al. 2018; Tobin et al. 2006; Susskind et al. 2011). This can lead to an underestimate of satellite-derived SBCAPE (Gartzke et al. 2017).

In an attempt to address this known deficiency, Dostalek et al. $(2017,2018)$ developed a correction of the NUCAPS boundary layer retrieval. The correction replaces NUCAPS surface temperature and dewpoint 


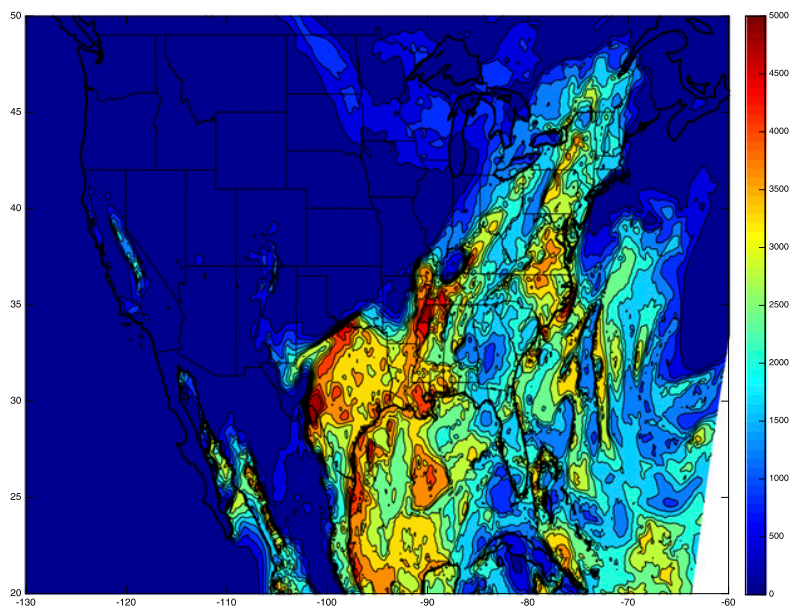

FIG. 7. The NAM CAPE analysis for 1800 UTC 18 Jun 2017.

temperature with nearby data from the Real Time Mesoscale Analysis (RTMA) (De Pondeca et al. 2011) and creates a new boundary layer by the use of a simplified mixed-layer model as described in Bowlan and Calhoun (2018). These experimental products are currently under evaluation by forecasters using the NWS Advanced Weather Interactive Processing System (AWIPS-II) visualization software at the NWS SPC during the annual HWT training sessions (Wheeler et al. 2018).

In this study, a purely observational approach is used to adjust the estimate of SBCAPE. Previous work by Gartzke et al. (2017) showed that there is poor correlation (0.3) between AIRS SBCAPE and coincident radiosondes, but the correlation dramatically improved (0.95) when the satellite surface parcel estimate was replaced by the radiosonde surface observation. The current paper describes a follow-on to the Gartzke et al. (2017) study with the following objectives: 1) develop an observation-only SBCAPE estimate using blended surface observations and satellite soundings, 2) create a near-real-time low-latency NUCAPS + surface observations SBCAPE product over CONUS using DB stations, and 3) demonstrate the near-real-time visualization of SBCAPE and other NUCAPS stability indices on any computer and hand-held device without the need for custom software. This work is not intended to validate NUCAPS or the combined NUCAPS + MADIS product, but to demonstrate the benefits of combining observational weather satellite profile data and surface observations.

A description of the data used in this study is provided in section 2, and the methodology used to create a merged product in section 3. An illustration of the merged product results is given in section 4 followed by conclusions. The appendix provides further detail of the near-real-time demonstration using SSEC's RealEarth.

\section{Data}

The surface data used in this study come from the NOAA Meteorological Assimilation Data Ingest System (MADIS) meteorological surface observations (https://madis.ncep.noaa.gov/). NOAA MADIS

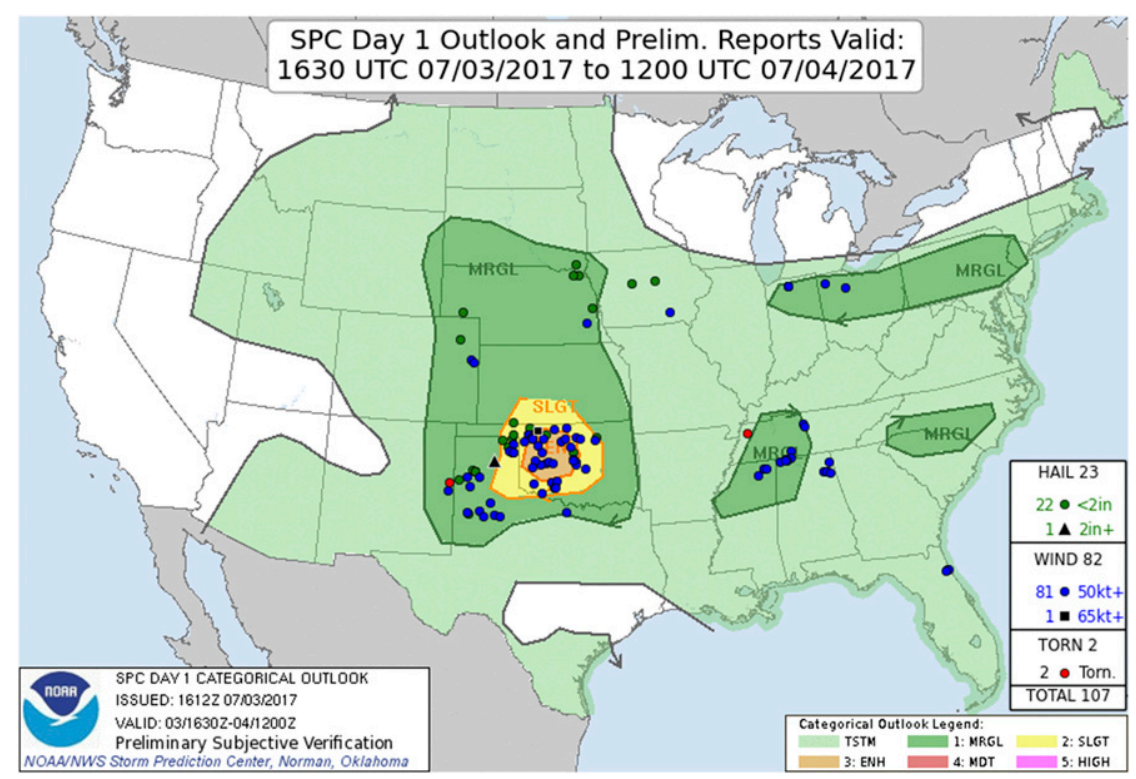

FIG. 8. SPC convective outlook for 1630 UTC 3 Jul 2017 and storm reports for the valid time (https://www.spc.noaa.gov/exper/archive/events/). 


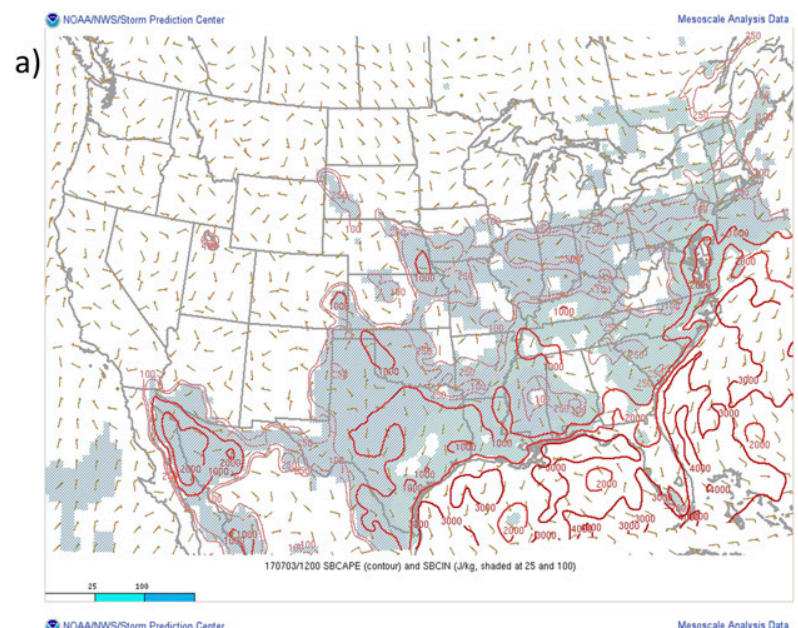

b)

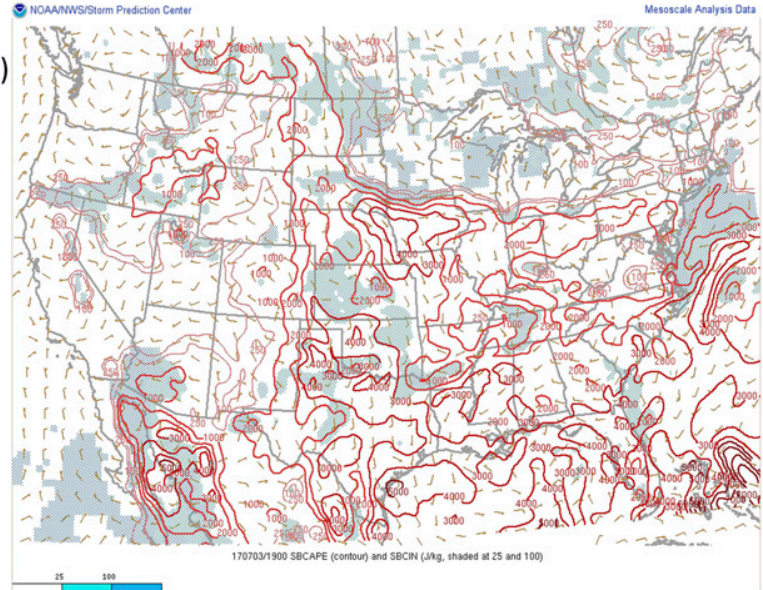

FIG. 9. SPC severe weather event archives mesoscale analysis of SBCAPE (red contours) and SBCIN (blue fill) for (a) 1200 and (b) 1900 UTC 3 Jul 2017.

provides a high density of surface station data with near-real-time availability. The NOAA MADIS system ingests the station data in real time, performs quality control, computes hourly averages, and creates an hourly output file containing all the station data over CONUS and selected stations from Canada and Mexico (Miller et al. 2005). A core network contained within MADIS is the NWS Automated Surface Observing Systems (ASOS), which are primarily located at airports around the United States. The density of MADIS stations is illustrated in Fig. 1. The high density of surface observations comes from transportation and other state and regional networks. The hourly MADIS surface observations used in this study are obtained from the public website (https:// madis-data.ncep.noaa.gov/madisPublic1/data/LDAD/ mesonet/netCDF/). The files obtained from MADIS are in netCDF format and the variables used in this study include surface temperature, dewpoint, latitude,
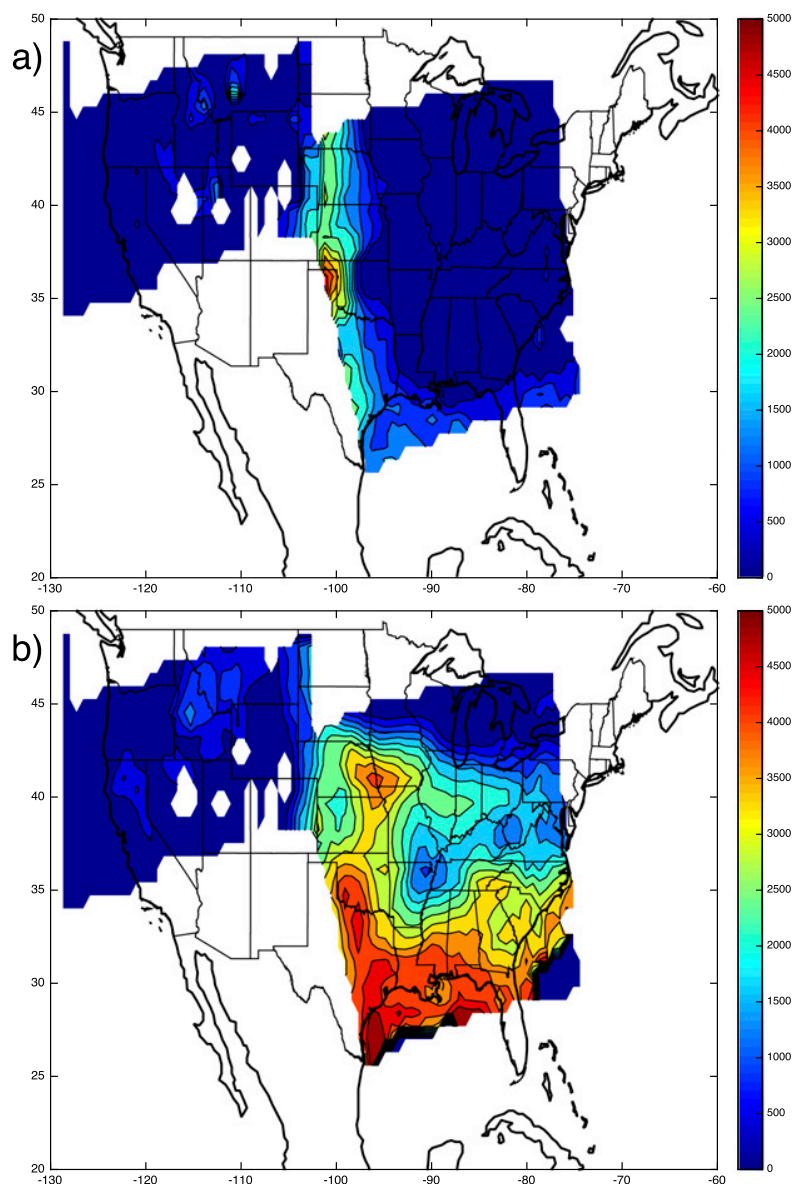

FIG. 10. As in Fig. 6, but for the case study from 1708 to 2210 UTC 3 Jul 2017.

longitude, pressure, and elevation for each hour of the day.

The satellite data used in the near-real-time application of this study are weather satellite data from SNPP obtained in near-real time from the DB systems at the University of Wisconsin-Madison SSEC, Hampton University in Hampton, Virginia, and the Naval Research Laboratory (NRL) in Monterey, California. The case study data from 2017 were processed using CSPP NUCAPS, version 1r0, while the 6-month analysis (AprilSeptember 2018) was processed using CSPP NUCAPS, version $2 \mathrm{r} 0$, from $S N P P$. (http://cimss.ssec.wisc.edu/cspp/). DB CSPP NUCAPS data are publicly available in nearreal time from the SSEC ftp site (ftp://ftp.ssec.wisc.edu/ $\mathrm{pub} / \mathrm{eos} \mathrm{db} / \mathrm{npp} / \mathrm{cris} /$ ). Within each overpass, the NUCAPS product files containing $32 \mathrm{~s}$ of sounding data are combined into a single data swath from just after the DB initial contact time to the time telemetry contact is lost at the receiver site. The variables used in this study from the NUCAPS netCDF file include time, latitude, longitude, topography, surface pressure, quality flag, 


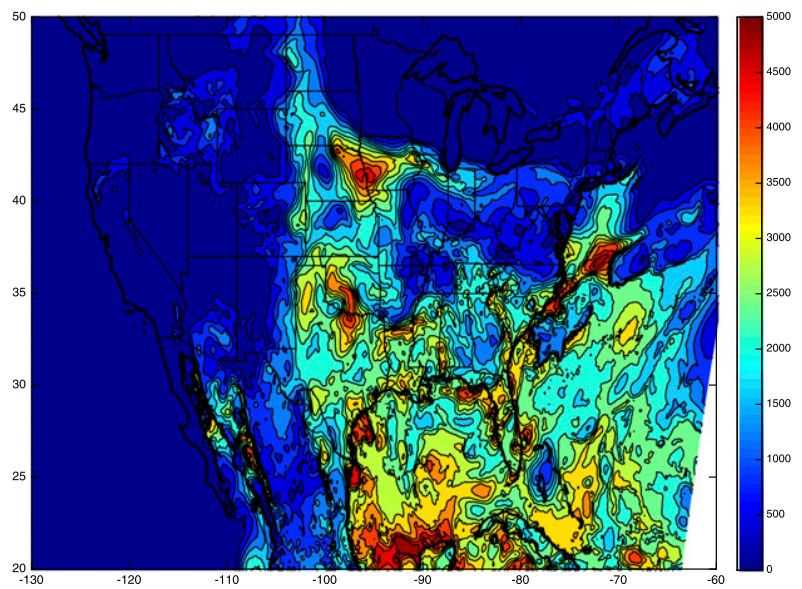

FIG. 11. NAM CAPE analysis for 1800 UTC 3 Jul 2017.

vertical pressure coordinate, and temperature and water vapor mixing ratio profiles. The pressure and temperature are level quantities, and the water vapor mixing ratio is a layer quantity (Gambacorta 2013). The methodology for handling the pressure levels and layers is described in section $3 b$. Note that the NUCAPS netCDF format files contain surface pressure, but do not contain an estimate for near-surface temperature or nearsurface water vapor mixing ratio. The method for estimation of the surface values is also described in section $3 b$.

\section{Methodology}

In this paper, the MADIS surface temperature and dewpoint observations are substituted for the nearsurface estimates from coincident NUCAPS vertical profiles of temperature and water vapor prior to the computation of SBCAPE to more accurately reflect the true surface parcel. This fixes a problem with the polarorbiting sounder estimates of the near-surface parcel, which have been shown to underestimate the temperature and dewpoint for atmospheric conditions where CAPE is greater than zero (Gartzke et al. 2017). Hourly MADIS surface observations are matched in space and time with NUCAPS vertical profiles on a spatial grid, and SBCAPE is calculated using the Sounding and Hodograph Analysis and Research Program in Python (SHARPpy) tool (Blumberg et al. 2017). This is a python software library derived from the National Center Sounding and Hodograph Analysis and Research Program (NSHARP) and SHARP software used at the Storm Prediction Center (Hart et al. 1999). The opensource software routines introduced in Halbert et al. (2015) are used to perform the CAPE calculations in this study. (The source code for SHARPpy was downloaded
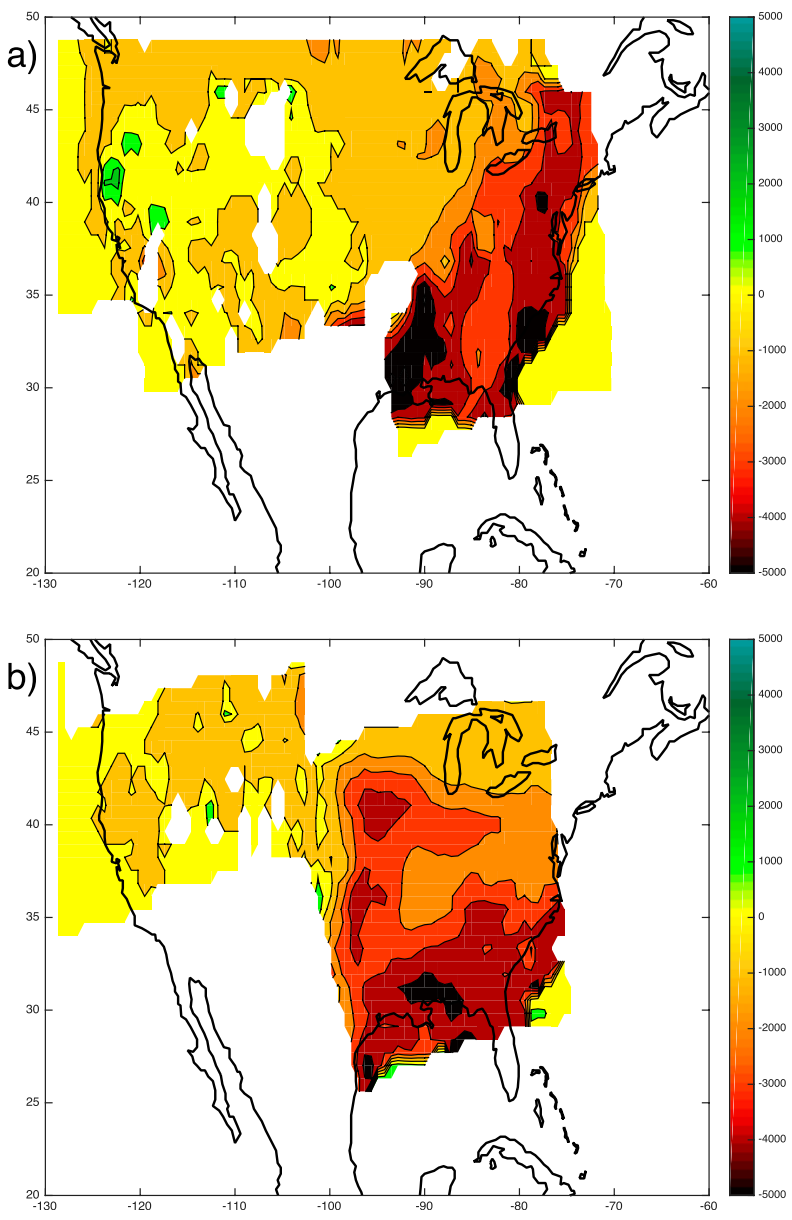

FIG. 12. (a) The SBCAPE difference of NUCAPS-only SBCAPE and the combined NUCAPS + MADIS SBCAPE for the 18 June 2017 case study for daytime overpasses between 1651 and 2151 UTC. (b) As in (a), but for the 3 Jul 2017 case study between 1708 and 2210 UTC.

from GitHub at https://github.com/sharppy/SHARPpy.) The "parcel" routine from the "params.py" module is used to compute CAPE and other instability parameters. The surface parcel temperature and dewpoint that is used in the SBCAPE SHARPpy calculation is from the input profile at the surface pressure. An automated process is used to compute SBCAPE on a $0.7^{\circ} \times 0.7^{\circ}$ grid for each overpass of the SNPP satellite using data from SSEC's DB antenna in near-real time. Subsequent satellite overpasses are merged onto the grid centered over CONUS. The contoured SBCAPE product is displayed in near-real time on SSEC's RealEarth. An example of the near-real-time visualization is shown in the appendix.

\section{a. MADIS surface data}

The MADIS data stream is used in this study because of the high station density across the United States as well as into Canada and Mexico and is a good fit to the 


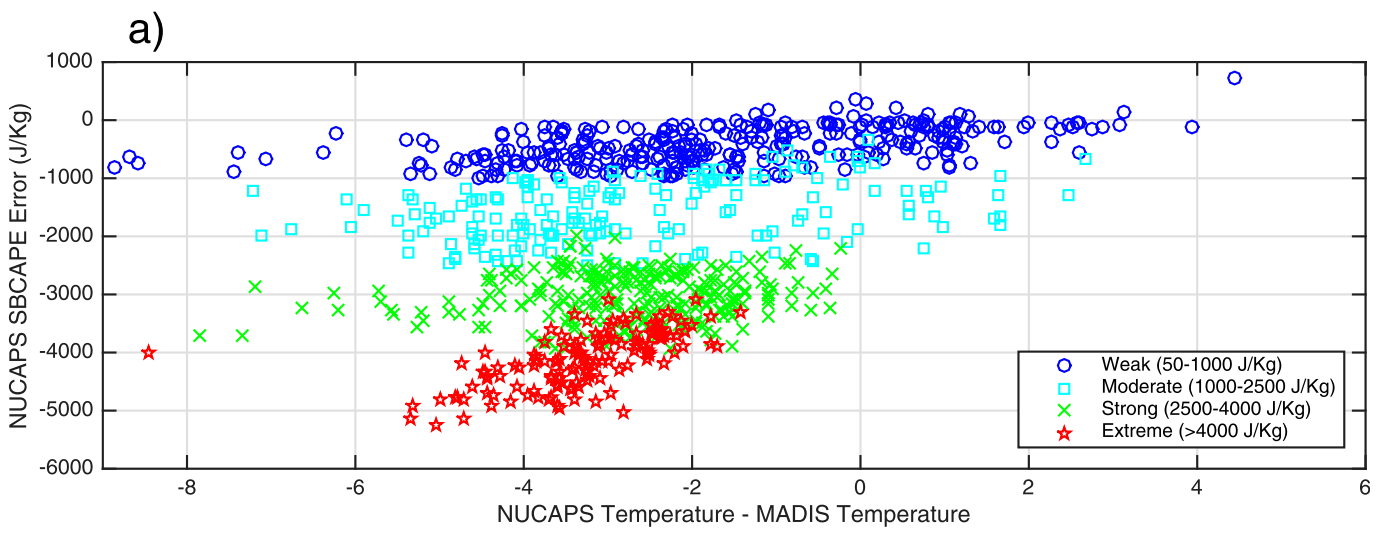

b)

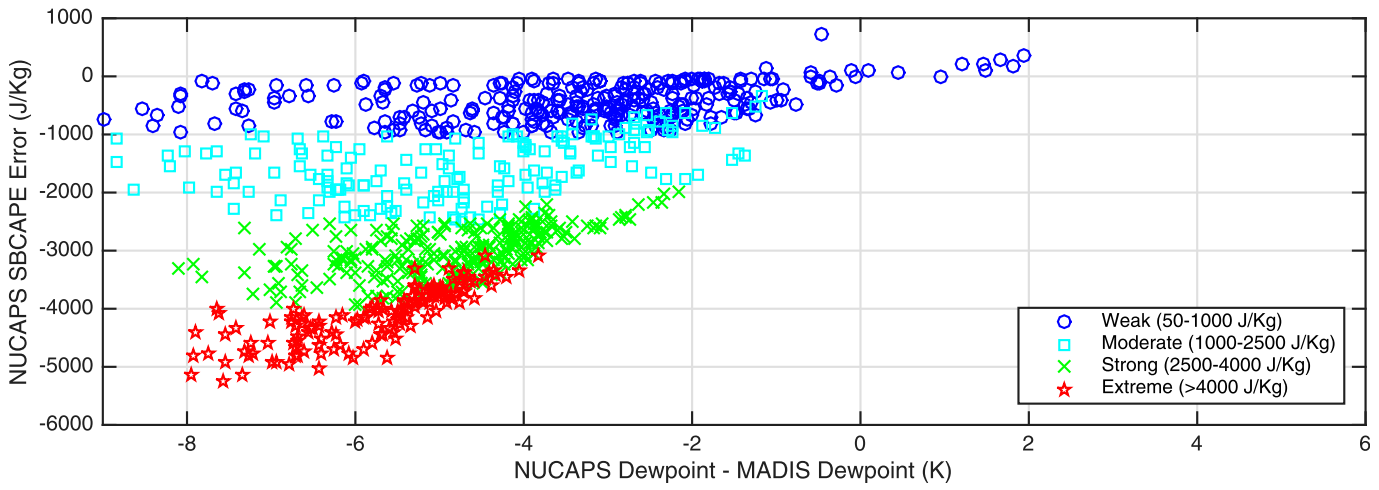

FIG. 13. Scatterplot comparing the SBCAPE difference between NUCAPS only and combined NUCAPS MADIS, and the difference between (a) surface temperature and (b) surface dewpoint of NUCAPS and MADIS for the 18 June 2017 case study. The symbols indicate the CAPE instability category of the combined NUCAPS + MADIS SBCAPE value.

NUCAPS nominal spatial resolution of about $50 \mathrm{~km}$. Hourly surface station data is obtained automatically from NOAA MADIS. There are 4 stages of quality checks for the MADIS meteorological surface data that are based on the NWS Techniques Specification Package (TSP) and are listed in the netCDF file. Stage 1 includes validity and position consistency checks, stage 2 includes temporal, internal, and model consistency checks, stage 3 includes spatial and statistical spatial consistency checks, and stage 4 is the Kalman filter. There is also a "reject list," where if observations are included in the list, they will be rejected if this quality control (QC) is applied. If any of the following QC flags are true for the MADIS temperature and dewpoint observations, the data are ignored and not included in the study: "No QC applied," "Passed QC stage 1," "Failed QC stage 1," "Passed QC stage 1, but failed stages 2 or 3," and "Included in reject list." After the quality control is applied, the surface observations are then put onto a $0.7^{\circ} \times 0.7^{\circ}$ grid, which is similar in size to the NUCAPS spatial resolution of about $50-75 \mathrm{~km}$.
Data from stations that fall within the same grid cell are averaged. Once the data are gridded, a $3 \times 3$ boxcar spatial convolution centered on each grid cell smooths the data to fill in missing grid cells. The method to convert MADIS station data to a contiguous grid over CONUS is illustrated in Fig. 2.

\section{b. NUCAPS profile data}

As indicated in section 2, the NUCAPS vertical profiles are routinely generated at the University of Wisconsin-Madison SSEC using CSPP software from data obtained at DB antenna sites, including one at the University of Wisconsin-Madison. This paper uses NUCAPS soundings from the SNPP satellite; however, the same methodology can be applied to the NOAA-20 polar-orbiting weather satellite and to the EUMETSAT MetOp series of weather satellites. The NUCAPS vertical profiles of temperature and water vapor mixing ratio are output on a fixed pressure scale with 100 vertical points (Gambacorta 2013). The same gridding and smoothing methodology described in section 3 a for the 


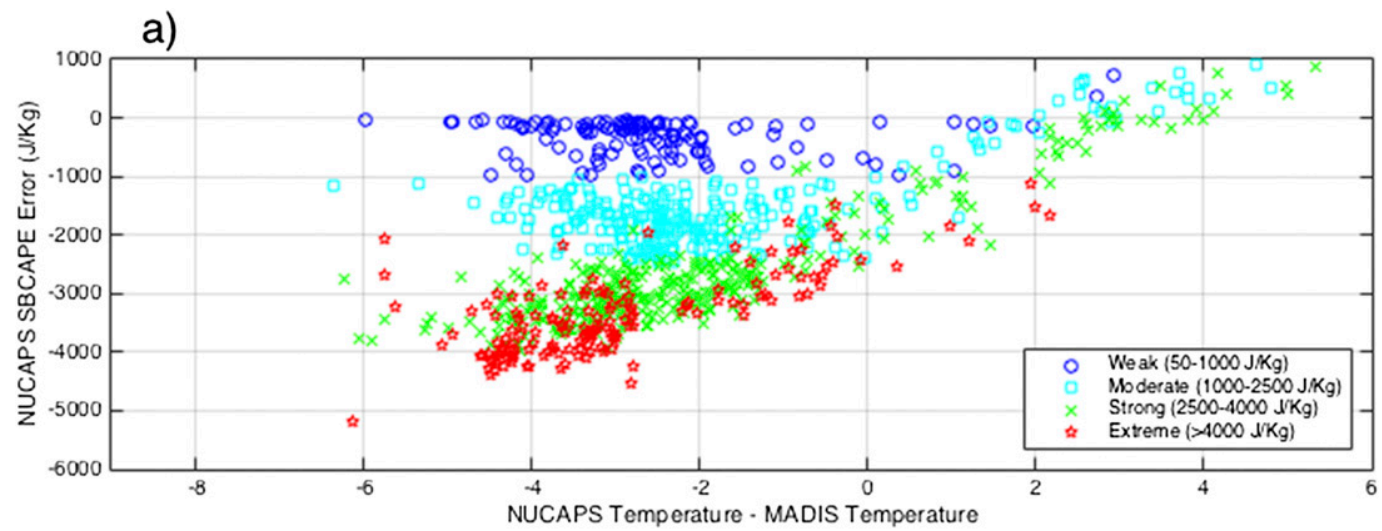

b)

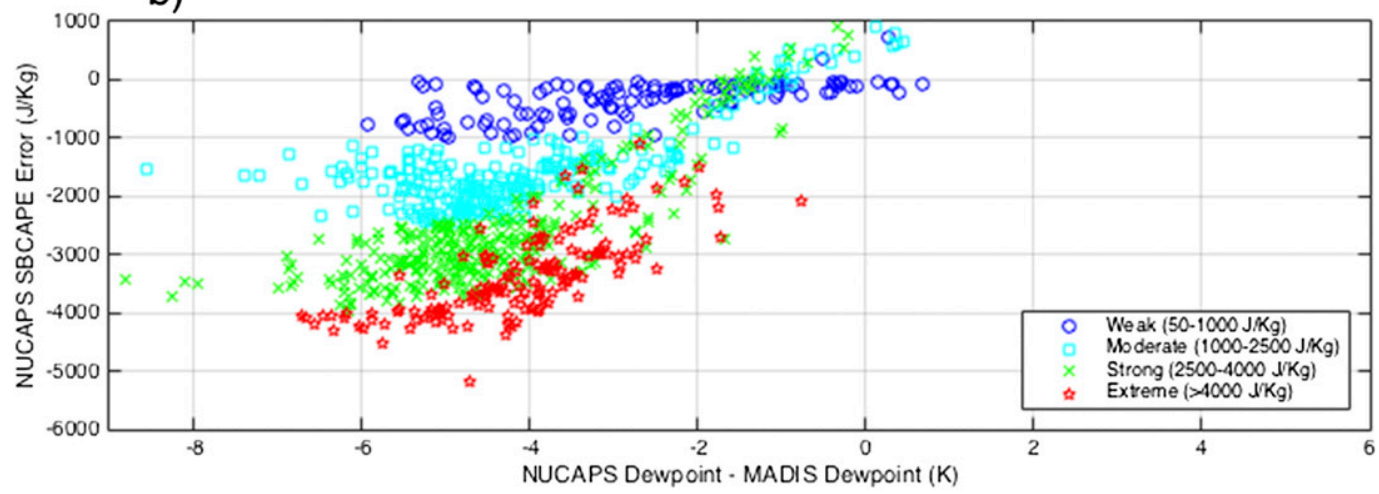

FIG. 14. As in Fig. 10, but for the 3 Jul 2017 case study.

MADIS surface observations was applied to each of the levels for both temperature and dewpoint. The dewpoint was converted from the NUCAPS pressure, temperature, and mixing ratio. An important detail to note is that the temperature profile is defined on pressurelevel boundaries, but the mixing ratio values represent the layer mean (Gambacorta 2013). In this study, the NUCAPS product mixing ratio profile is converted from layers to levels by interpolation from the layer mean pressure to the NUCAPS fixed pressure levels. Then the level mixing ratio values, the level temperature values, and the level pressure values are used to calculate the dewpoint using the Goff-Gratch formulation from the sixth revised edition of Smithsonian Meteorology Tables (Lowe 1977; Goff and Gratch 1946).

A special method is required to compute the NUCAPS near-surface dewpoint from the NUCAPS fixed pressure levels. To calculate these quantities, the first valid layer of water vapor mixing ratio is multiplied by the factor

$$
f_{l_{b}} \equiv \frac{p_{s}-P_{l_{b-1}}}{P_{l_{b}}-P_{l_{b-1}}}
$$

[Eq. (7) from Nalli et al. (2013)], where $p_{s}$ is the surface pressure, $P_{l}$ is the level pressure, and the index $l_{b}$ denotes the first valid level in the sounding profile closest to the surface. This formula accounts for the manner in which the water vapor column density is assigned to the NUCAPS output files by layer. The bottom-layer dewpoint is then calculated from the bottom-layer water vapor mixing ratio using an estimate of the layer pressure and layer temperature. The explicit assumption used in this study is that the NUCAPS retrieval of the mean layer closest to the surface is a valid estimate of the near-surface mixing ratio. In particular, there is not enough information in the satellite observations to determine the near-surface water vapor content at the $2-\mathrm{m}$ height, but there could be skill in the determination of the layer column density above the surface. This issue is an active focus of current calibration and validation activities for the NUCAPS operational product, which are using similar analyses of SBCAPE to assess the NUCAPS performance in the atmospheric boundary layer. The CSPP NUCAPS retrieval is expected to be different from the operational NUCAPS retrieval. NUCAPS operates a cloud-clearing scheme on the basis of a cluster of adjacent fields of view (FOVs). 


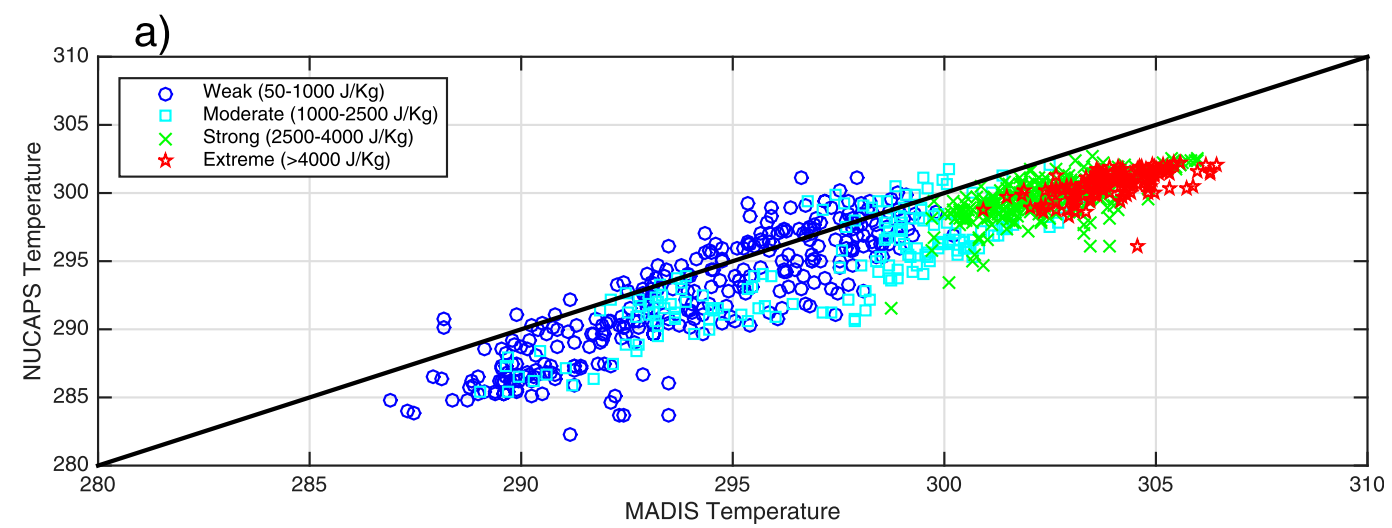

b)

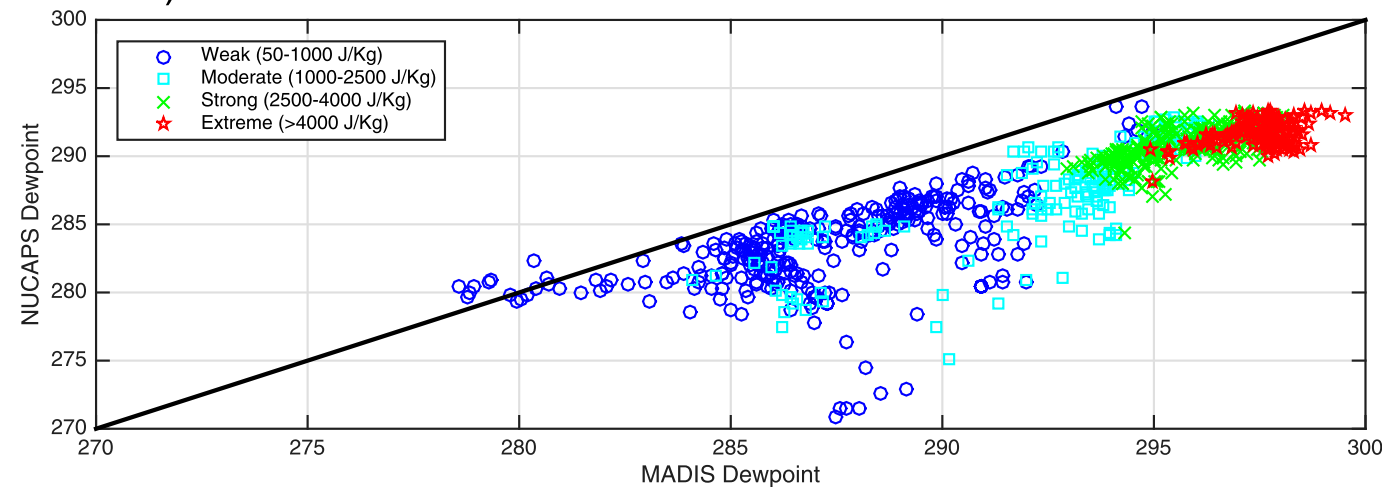

FIG. 15. Scatterplot of NUCAPS and MADIS (a) surface temperature and (b) dewpoint for the 18 Jun 2017 case study. The symbols indicate the CAPE instability category of the combined NUCAPS + MADIS SBCAPE value.

The operational software uses 9 FOVs. Because of limitations in the downlink bandwidth of the direct broadcast antenna, the CSPP software uses 7 FOVs. Preliminary comparisons of operational NUCAPS from NOAA CLASS and DB CSPP indicate differences in SHARPpy calculations of SBCAPE that can be significant. However, when MADIS surface observations are used as the surface parcel in the CAPE calculation, the differences between CLASS and CSPP are minimal. In this study, CSPP NUCAPS is used because of the nearreal-time availability of the data.

\section{c. Surface-based CAPE}

To merge the surface observations with the satellite profiles, the different observation times must be considered. The MADIS surface data are hourly, but the NUCAPS data vary in time because of day-to-day variations in the local satellite overpass times. The NUCAPS data are matched with the closest hourly MADIS file to the satellite overpass time. An example of this matchup is shown in Fig. 3. The NUCAPS overpass covering the eastern United States at 1827 UTC was matched with the 1800 UTC MADIS surface observation time. The subsequent NUCAPS overpass covering the central United States occurred at 2009 UTC and was matched to the 2000 UTC MADIS surface observations.

The SHARPpy software, which is used to calculate the SBCAPE, was designed for use with NWS radiosondes, which are defined on pressure levels, not layers. For this reason, a table of values for the 100 NUCAPS fixed pressure levels is constructed containing height, pressure, temperature and dewpoint. Once the MADIS and the NUCAPS files are gridded and matched in time, the MADIS surface 2-m temperature and surface 2-m dewpoint replace the NUCAPS surface data. The height above ground for each pressure level is calculated using the hypsometric equation. Using the height profile, an interpolation of the NUCAPS profiles to 202 height levels as described in Gartzke et al. (2017) was conducted. This interpolation improves the vertical integration used in the SHARPpy calculation of SBCAPE.

\section{Results}

Two cases during the summer of 2017 were selected to illustrate the near-real-time characteristics of the blending of surface observations with NUCAPS satellite-derived 


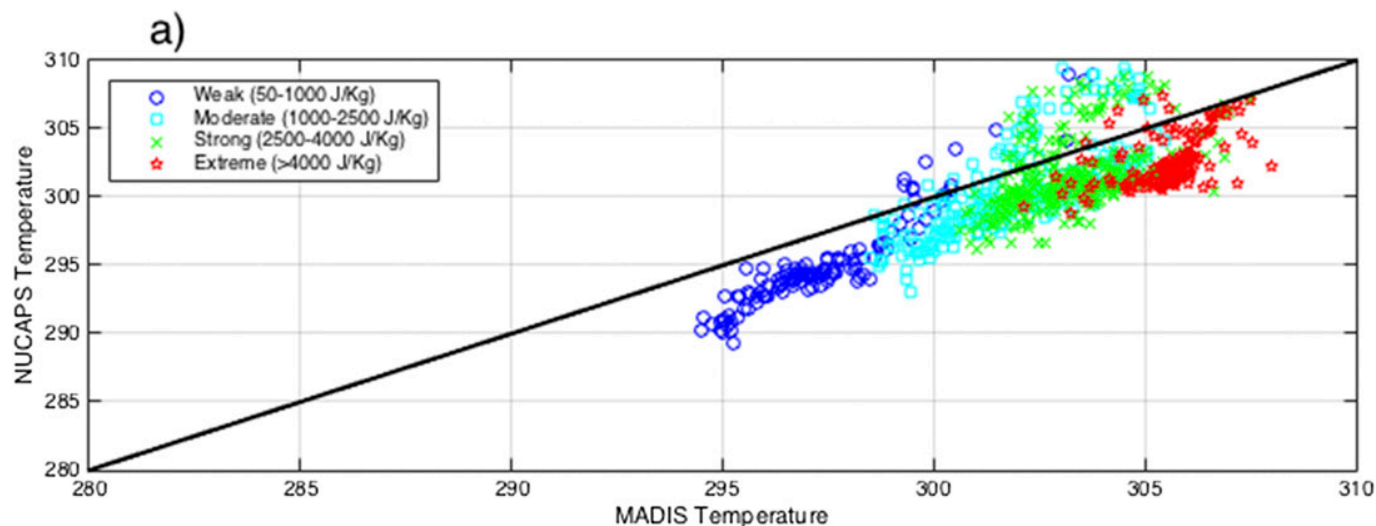

b)

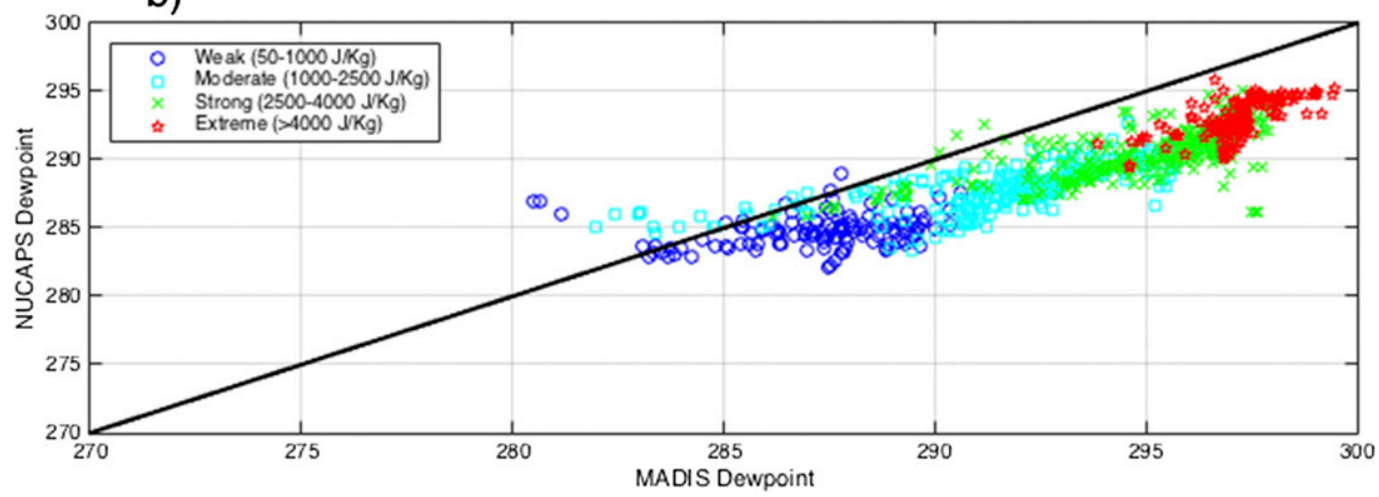

FIG. 16. As in Fig. 13, but for the 3 Jul 2017 case study.

temperature and moisture soundings. The results indicate the dramatic impact that the use of surface observations can have on the estimates of CAPE when using satellite-derived thermodynamic profiles. These cases were chosen because they are representative of conditions with a warm, moist boundary layer and high observed CAPE values. Finally, a comprehensive analysis in the CONUS region is presented for the 6-month time period, April-September 2018, which covers the most convectively active time of the year.

\section{a. 18 June 2017 case study}

On 18 June 2017, severe storms occurred throughout the eastern United States that brought damaging hail and strong winds. Storm reports from the SPC website are shown in Fig. 4. According to the SPC severe weather events archive, the atmospheric conditions leading to the storms that occurred later in the day were conducive to convective initiation (spc.noaa.gov/exper/ archive/events/). In the eastern United States, dewpoint values remained high throughout the day starting at 0900 UTC with surface dewpoint values ranging from the low 60s in the Northeast to the high 60s and low 70s $\left({ }^{\circ} \mathrm{F}\right)$ in the southeast in South and North Carolina, Tennessee, Georgia, and Florida (https://www.spc.noaa.gov/exper/
surfaceMaps/). These values remained fairly consistent throughout the day, creating a moist boundary layer, and around 1930 UTC, the SPC mesoscale discussion 1087 stated "surface dewpoints [are] holding in the middle 60s to lower 70 s $\left({ }^{\circ} \mathrm{F}\right)$ " in central Pennsylvania, New York, and Vermont. The region described in the mesoscale discussion is outlined in Fig. 4. Temperatures for the same area ranged from the low to high 70 s $\left({ }^{\circ} \mathrm{F}\right)$ at $0900 \mathrm{UTC}$ and steadily increased. By 1800 UTC, temperatures were in the mid- to high $80 \mathrm{~s}\left({ }^{\circ} \mathrm{F}\right)$. The MADIS surface observations during this time shown in Figs. $3 \mathrm{c}$ and $3 \mathrm{~d}$ are consistent with the SPC surface observations and the mesoscale discussion for dewpoint values around 1800 UTC. Figure 3 also illustrates that the NUCAPS surface estimate had much lower dewpoint values than those observed by MADIS station observations at the time of the overpass.

At 1200 UTC 18 June 2017, the East Coast boundary layer was stable, with SBCAPE values from 0 to $1000 \mathrm{~J} \mathrm{~kg}^{-1}$ and surface-based convective inhibition (CIN) values around $-100 \mathrm{~J} \mathrm{~kg}^{-1}$ according to the mesoscale analysis data graphic from the SPC severe weather event archive shown in Fig. 5a. CIN represents the negatively buoyant force that prevents free convection and is used alongside CAPE in forecasting. 
Throughout the day, inspection of the hourly trends in the mesoscale analyses showed the CIN eroded as the boundary layer warmed from diurnal heating. As the day progressed, the SPC severe weather event archive shows the SBCAPE also increased along the East Coast with values around $2000-3000 \mathrm{~J} \mathrm{~kg}^{-1}$ at $1800 \mathrm{UTC}$ as seen in Fig. 5b.

The NUCAPS-only result for the overpass occurring at 1827 UTC shows low or zero values of SBCAPE for most of the East Coast (Fig. 6a). The result of the SBCAPE computed from NUCAPS profiles with the MADIS surface estimate is shown in Fig. 6b. Comparing this to Fig. 5b shows that the NUCAPS-only estimate did not capture the large SBCAPE values for this time. However, when the NUCAPS profile is combined with the MADIS surface data, the SBCAPE estimate shown in Fig. $6 \mathrm{~b}$ for the same overpass more closely matches the SPC mesoscale analysis SBCAPE (Fig. 5b). These dramatic differences in SBCAPE derive from the differences between the NUCAPS and the MADIS surface temperature and dewpoint shown in Fig. 3. The combined NUCAPS + MADIS product depicted areas of high SBCAPE before the storms occurred in the eastern states, especially in Pennsylvania and western New York, where many of the storm reports were documented. The North American Mesoscale Forecast System (NAM) reanalysis at 1800 UTC 18 June 2017 shown in Fig. 7 displays similar patterns and magnitudes of the combined NUCAPS + MADIS SBCAPE shown in Fig. $6 \mathrm{~b}$ around the same time as the NUCAPS overpass (Rogers et al. 2009). The NUCAPS-only estimate did not accurately reflect this area of high SBCAPE. The combination of accurate surface observations with the NUCAPS vertical temperature and dewpoint profiles provides a greatly improved estimate of SBCAPE on this date.

\section{b. 3 July 2017 case study}

On 3 July 2017, a mesoscale convective system (MCS) developed in the Oklahoma and Texas Panhandles and central Oklahoma that resulted in large hail and strong winds according to the SPC storm report (Fig. 8). The SPC mesoscale analysis data graphics from the Severe Weather Event Archive aided in visualizing the atmospheric conditions leading up to the storms on this day (spc.noaa.gov/exper/archive/events/). At 1200 UTC, the environment was fairly stable, with SBCAPE values ranging from 0 to $1000 \mathrm{~J} \mathrm{~kg}^{-1}$ (Fig. 9a). CIN values were high in the morning, exceeding $-100 \mathrm{~J} \mathrm{~kg}^{-1}$. Throughout the day, the CIN eroded as the temperature and dewpoint temperature increased. A warm, moist boundary layer was present, with temperatures from the high 60 s to low 70 s $\left({ }^{\circ} \mathrm{F}\right)$ and dewpoint temperatures ranging from $60^{\circ}$ to $70^{\circ} \mathrm{F}$

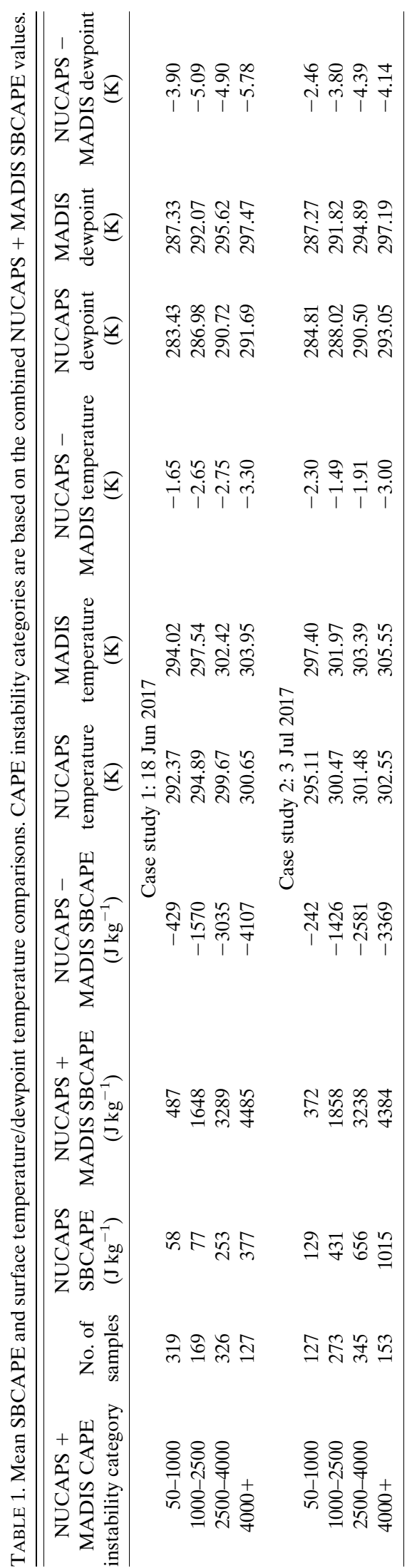


a)
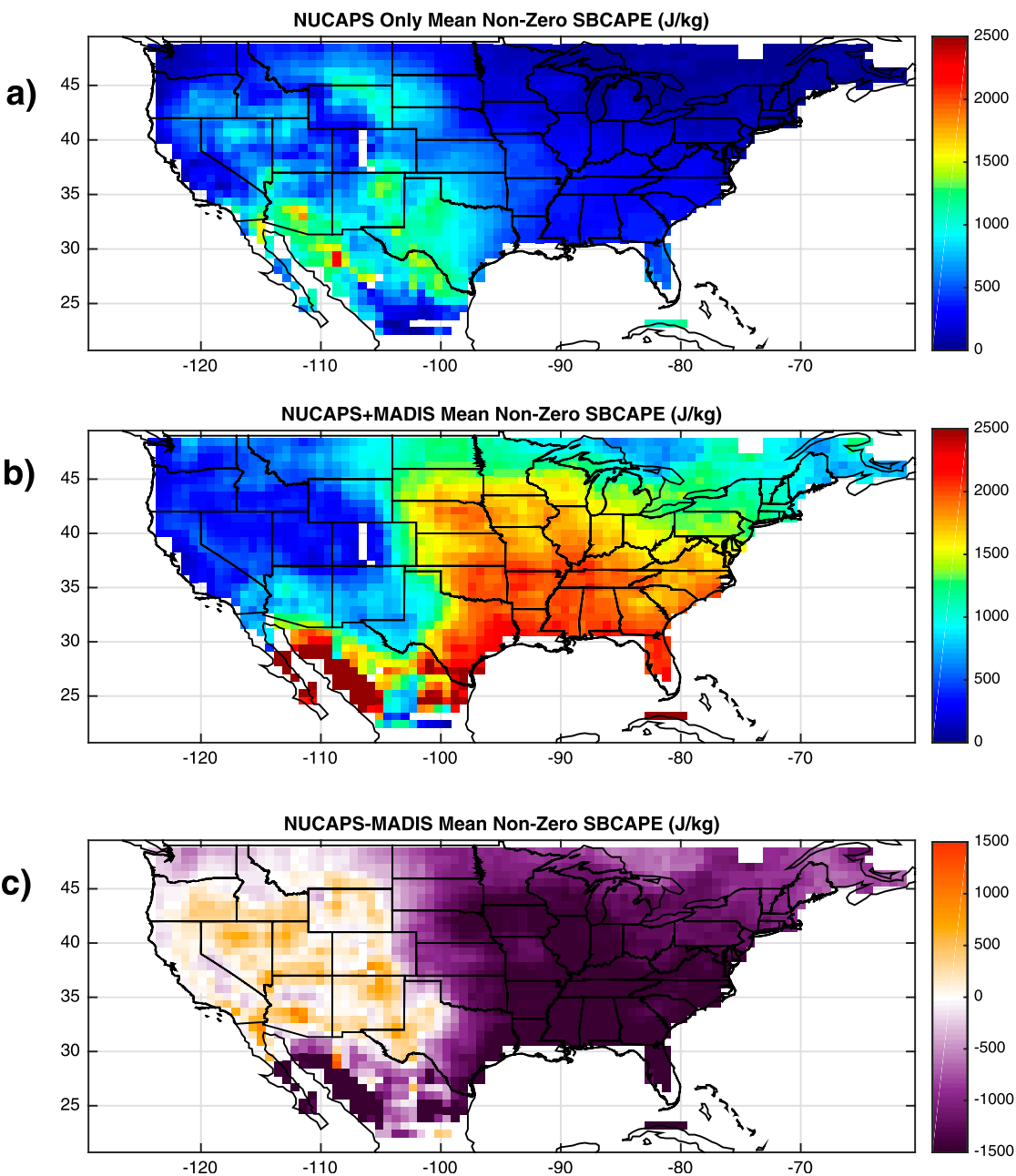

FIG. 17. Mean values of nonzero SBCAPE over the 6-month period from April to September 2018, for (a) NUCAPS only, (b) NUCAPS + MADIS, and (c) their difference.

in the Texas and Oklahoma Panhandles and central Oklahoma (https://www.spc.noaa.gov/exper/surfaceMaps/). By 1900 UTC, there was minimal CIN present in the Oklahoma and Texas Panhandles, and SBCAPE values ranged from 2500 to $4000 \mathrm{~J} \mathrm{~kg}^{-1}$ (Fig. 9b). The range of temperatures in this area rose to the low 80 s to low $90 \mathrm{~s}\left({ }^{\circ} \mathrm{F}\right)$, and the dewpoint temperatures remained fairly constant.

Figure 10 shows another example of the dramatic differences in the SBCAPE calculation that result from the combined satellite and surface values for this case study. Much like the 18 June 2017 case, the NUCAPSonly estimate of SBCAPE does not reflect high SBCAPE values throughout the severe weather areas in Oklahoma and the Texas Panhandle (Fig. 10a). Figure 10b (NUCAPS + MADIS) shows SBCAPE values from 2500 to $5000 \mathrm{~J} \mathrm{~kg}^{-1}$ where the MCS develops in the Texas and Oklahoma Panhandles and in central Oklahoma, whereas Fig. 10a (NUCAPS only) does not capture the high SBCAPE values in the area of the storm's formation. The high SBCAPE values from NUCAPS + MADIS are more consistent with the SPC analysis shown in Fig. 9b. The NAM CAPE analysis for 1800 UTC is shown in Fig. 11. The NUCAPS profile merged with the MADIS surface data observe the strong gradient of SBCAPE in northern Iowa into southern Wisconsin that is also captured in the NAM model analysis. The NUCAPS + MADIS and the NAM analysis both observe strong SBCAPE values through Texas, Louisiana, and Mississippi. This case study also exhibits the value of the combined use of satellite profiles and surface observations.

\section{c. Case study statistics}

To quantify the impact of using MADIS surface observations in these cases, the difference was computed between NUCAPS-only SBCAPE and the combined NUCAPS and MADIS SBCAPE, as seen in Fig. 12. 
Some of the largest differences for both case studies in SBCAPE are located in areas that received severe weather. Figure 12 also shows that the majority of differences in SBCAPE are negative, meaning the NUCAPS-only estimate is underestimating the strong and extreme SBCAPE values. These large SBCAPE errors are due to the differences in surface temperature and surface dewpoint between the NUCAPS retrieval estimate and the MADIS surface observations as seen in Fig. 13. For all of the CAPE values categorized as "extreme instability," the NUCAPS-only temperature and dewpoint values were underestimated in the 18 June 2017 case. A similar result is seen in the 3 July 2017 case shown in Fig. 14. In both cases, NUCAPS surface estimates have a significant dry bias in dewpoint and a slight cold bias in temperature relative to surface $2-\mathrm{m}$ height observations. This is illustrated in Figs. 15 and 16. The mean differences of each CAPE instability category are summarized in Table 1 . This table also shows that for higher SBCAPE values, NUCAPS only has a larger dry bias, which leads to a large SBCAPE error in both of the case studies. These two case studies highlight strong and extreme SBCAPE; however, it should be noted that moderate and weak SBCAPE are also important to accurately measure, as this weaker instability can be an important ingredient in convection.

\section{d. April-September 2018 statistics}

In addition to the two case study days, a DB CSPP NUCAPS dataset from April to September 2018 has been analyzed to provide a comprehensive characterization of the NUCAPS-only SBCAPE compared with the combined NUCAPS + MADIS SBCAPE. The nonzero SBCAPE values from NUCAPS + MADIS were averaged over the 6-month time period. The corresponding NUCAPS-only cases matched in time and space were used to create a one-to-one comparison using NUCAPS-only and NUCAPS + MADIS SBCAPE. The time averages and the difference between the averages are illustrated in Fig. 17. This figure shows the regional affects the MADIS observations have on the NUCAPS SBCAPE. In the eastern United States, the NUCAPS + MADIS SBCAPE is on the order of $2000 \mathrm{~J} \mathrm{~kg}^{-1}$ on average greater than NUCAPS-only SBCAPE. In certain regions in the western United States, the NUCAPS + MADIS SBCAPE is on average $500 \mathrm{~J} \mathrm{~kg}^{-1}$ less than the NUCAPS-only SBCAPE estimate. The net effect of MADIS surface observations is an increase in SBCAPE in the eastern United States and a decrease in the western United States. For a more complete assessment, the averages and the number of samples of each CAPE instability category are presented in Table 2. In contrast to the several hundred samples in the case studies, the 6-month period contains more than

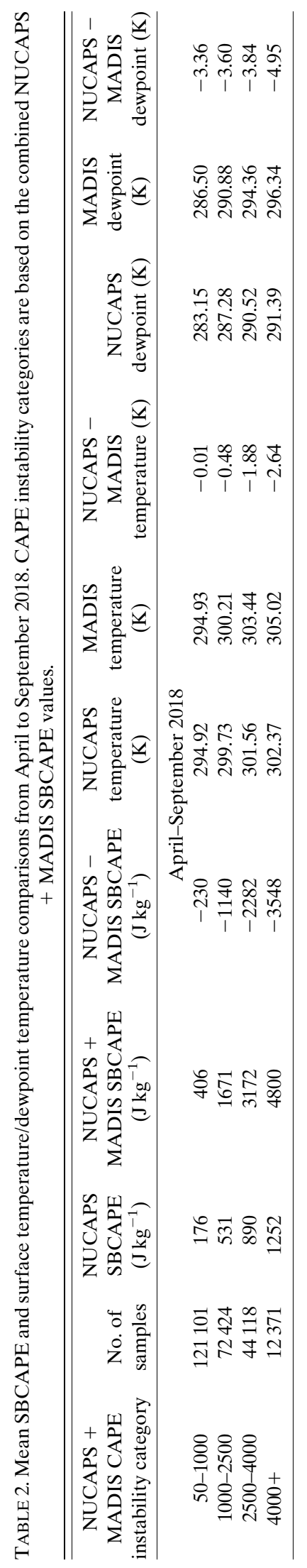


a)
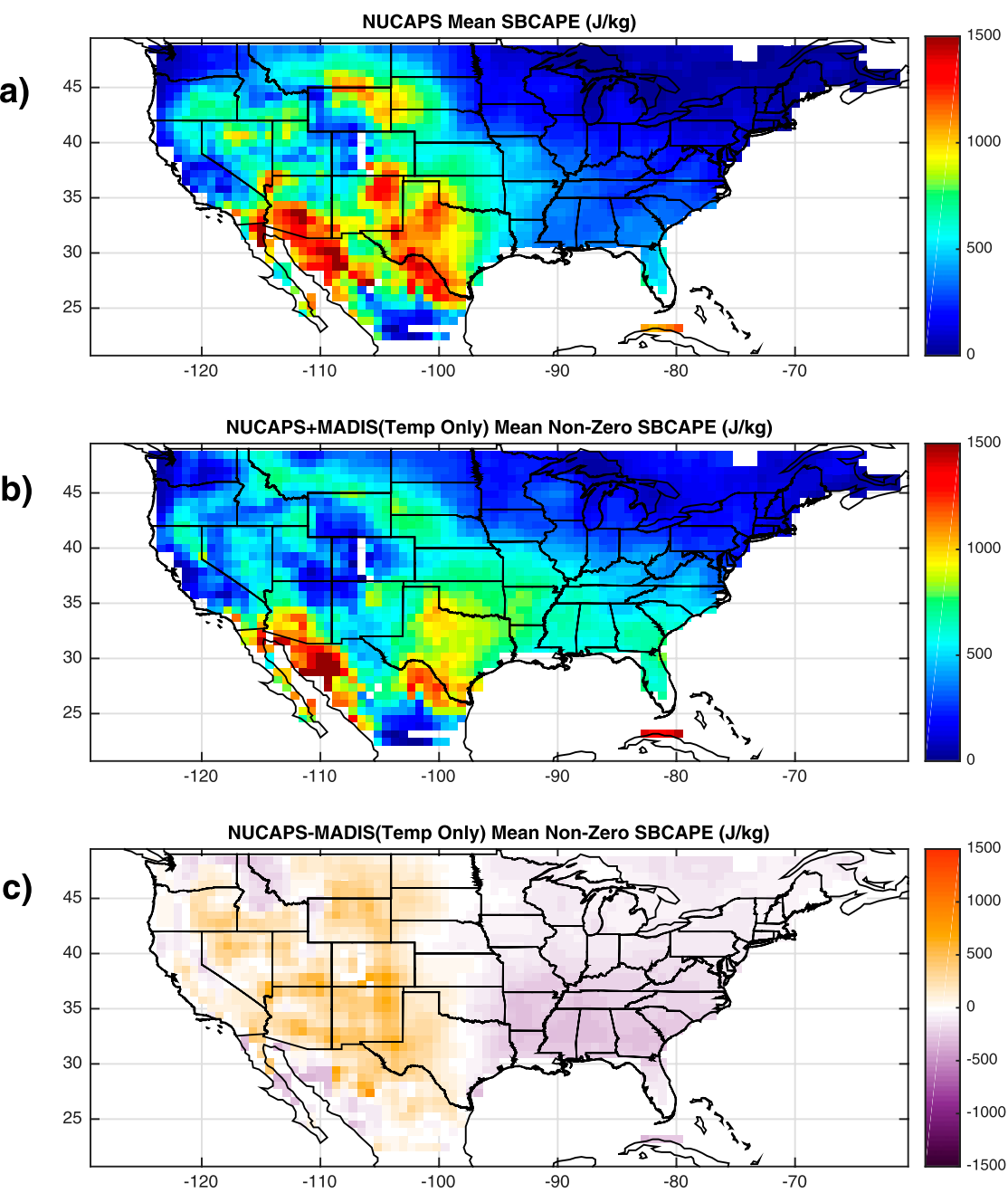

FIG. 18. As in Fig. 17, but only MADIS temperature is used in the SBCAPE calculation.

200000 nonzero CAPE samples. Despite the larger statistics, the differences in SBCAPE and in the near-surface air temperature and dewpoint for the 6-month period are very consistent with the case study results in Table 1 . These results are also consistent with the 10-yr statistical analysis presented in Gartzke et al. (2017), which evaluated NASA AIRS, version 6, soundings (Susskind et al. 2014).

To understand the individual effects of the MADIS surface temperature and dewpoint, the NUCAPS + MADIS SBCAPE was calculated using the MADIS surface temperature while retaining the NUCAPS surface dewpoint value (Fig. 18). The differences observed in Fig. $18 \mathrm{c}$ between the NUCAPS-only and NUCAPS + MADIS temperature SBCAPE are fairly minimal $\left(500 \mathrm{~J} \mathrm{~kg}^{-1}\right)$. The MADIS dewpoint-only study was done by calculating the NUCAPS + MADIS SBCAPE using the MADIS surface dewpoint, while the NUCAPS surface temperature retrieval was retained (Fig. 19). In this case, the differences in the SBCAPE calculation are much larger than when only the MADIS temperature was used. Figure 19c shows differences on the order of 1000 $1500 \mathrm{~J} \mathrm{~kg}^{-1}$ throughout the Midwest and eastern United States, and is similar to the combined effect of changing both surface temperature and dewpoint shown in Fig. 17c. Therefore, we conclude that the dry bias in the NUCAPS surface dewpoint used in this study was the primary cause of the NUCAPS-only low SBCAPE values.

\section{Conclusions}

Satellite hyperspectral infrared soundings can be useful in forecasting severe weather events occurring between synoptic radiosonde launches. However, satellite-derived stability indices such as CAPE can suffer from a lack of information in the satellite measurement of the boundary layer. SBCAPE is important because it can identify an unstable atmosphere, which is a key ingredient in convection and severe weather. 
a)

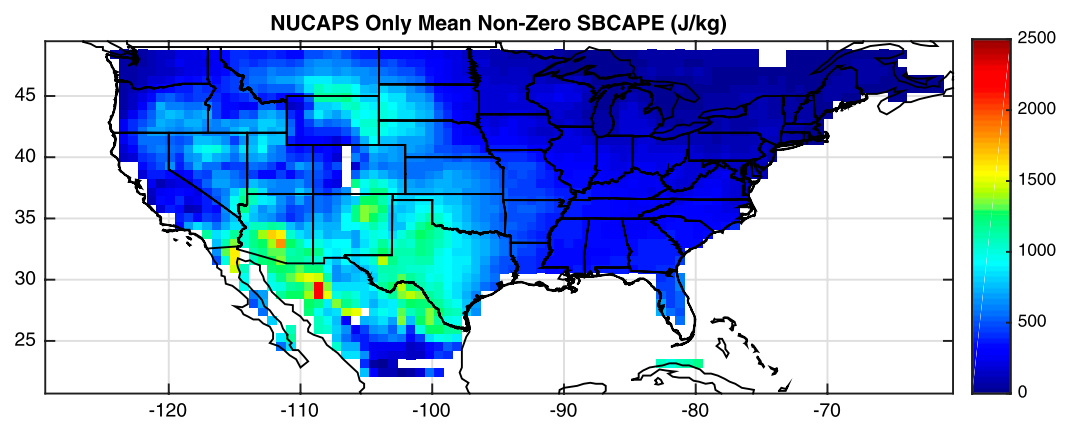

b)
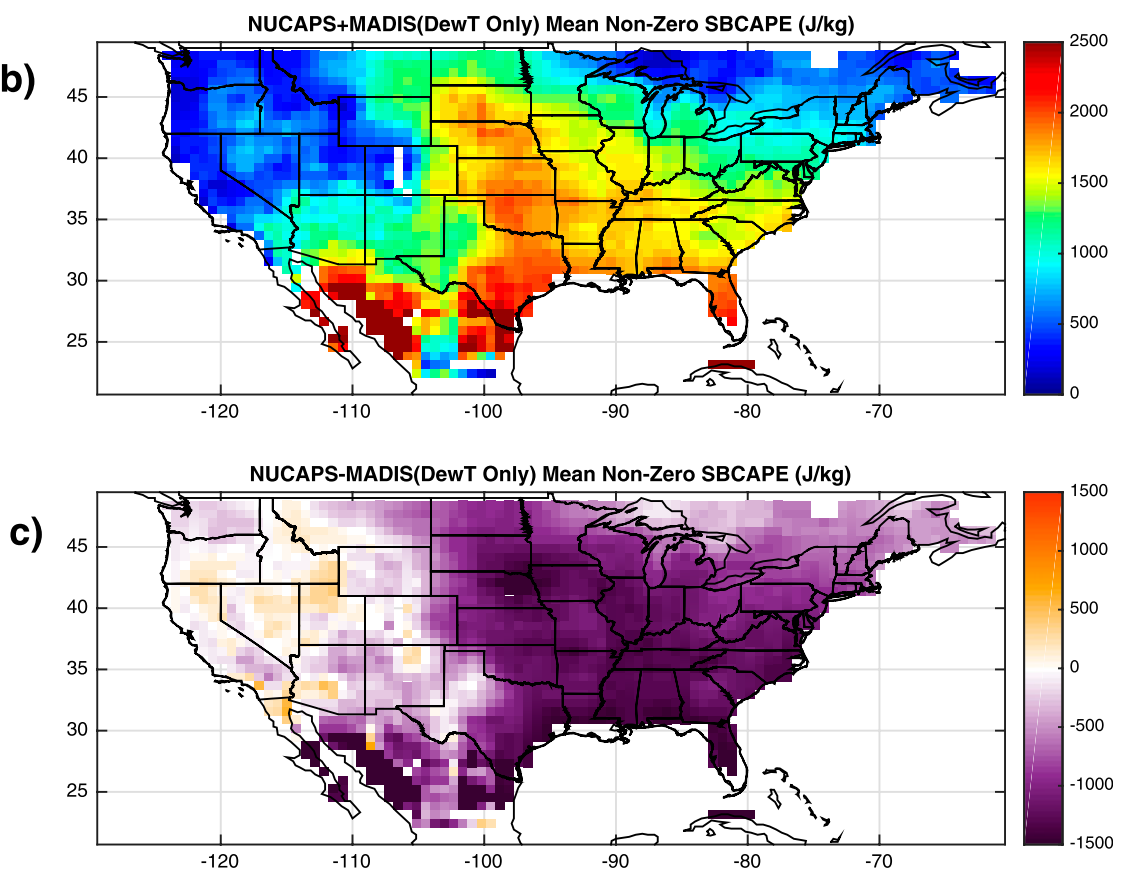

FIG. 19. As in Fig. 17, but only MADIS dewpoint is used in the SBCAPE calculation.

In this study, it was found that there is a large difference between the SBCAPE calculated using NUCAPS satellite-only data and the SBCAPE calculated using surface observations merged with satellite-retrieved profiles. This difference is attributed to an inherent characteristic of the passive sounding, which provides an average over a thick layer near the surface. This leads to an underestimation of the surface temperature and dewpoint for moist daytime cases, which leads to an underestimate of SBCAPE, particularly in strong instability cases. A difference of less than a degree in surface temperature and dewpoint can result in a dramatically different SBCAPE value. The assessment of the 6-month period between April and September 2018 determined the dry bias in the NUCAPS surface dewpoint temperature is the primary cause of the underestimation of the NUCAPS-only SBCAPE estimate. The combination of the MADIS surface observation data and the NUCAPS satellite profile data improves the agreement with the SPC mesoscale analysis and the NAM analysis compared to the NUCAPS-only SBCAPE estimate. This combined observational product can provide forecasters with additional information to compare to model analyses, in particular, the location of unstable air masses at the time of the satellite overpass, which may differ from the forecast.

This study has demonstrated near-real-time SBCAPE generation using hourly MADIS data merged with coincident satellite direct broadcast NUCAPS products from operational polar-orbiting weather satellites. The results are consistent with those of Gartzke et al. (2017), which compared AIRS-derived SBCAPE to coincident Vaisala radiosondes. The results in this paper complement those in Iturbide-Sanchez et al. (2018) by providing an additional assessment of SBCAPE derived from operational NUCAPS profiles. While this study focused on a low-latency direct broadcast product, the results will be used to improve future versions of the global 


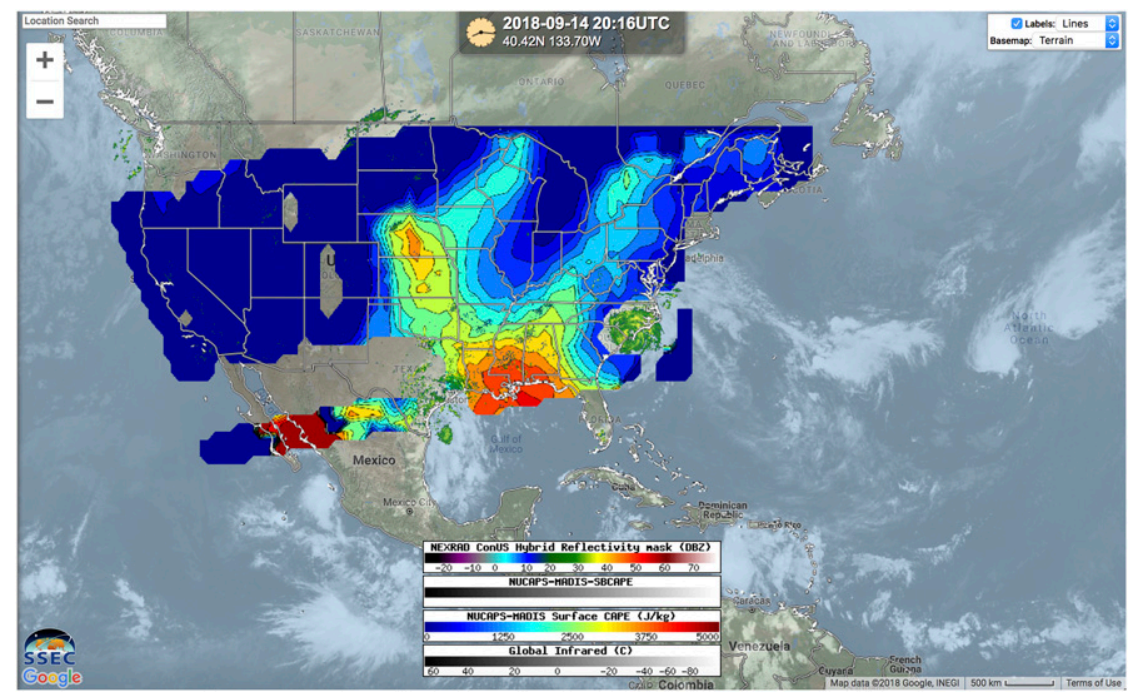

FIG. A1. Example of NUCAPS + MADIS SBCAPE displayed on RealEarth along with the global infrared overlay and radar for 14 Sep 2018. Valid from 1834 (East Coast) to 2016 (West Coast) UTC during the landfall of Hurricane Florence.

operational NUCAPS product. Future work includes assessing the accuracy of other severe weather indices, in particular CIN. In addition, the spatial resolution of the MADIS product will be improved by the use of a finer grid, which may provide enhanced small-scale structure information on SBCAPE. The near-real-time direct broadcast demonstration will be extended to include NUCAPS retrievals obtained from the operational NOAA-20 satellite in the early afternoon polar orbit and the latemorning overpasses of the MetOp satellites. The combined use of NUCAPS + MADIS SBCAPE obtained from these operational weather satellites will provide additional time sampling useful to capture the diurnal trend of a preconvective or convective environment that can lead to severe weather.

Acknowledgments. This work was partly supported by the NOAA JPSS Cal/Val program (Grant NA15NES4320001).

\section{APPENDIX}

\section{Near-Real-Time Display of Combined NUCAPS + MADIS Products}

In this study, near-real-time data are emphasized because of the importance of using the satellite sounding information to observe the preconvective environment. The NUCAPS profiles from direct broadcast allow these products to run in near-real time with a latency of 15$30 \mathrm{~min}$ after each overpass. Forecasters at the HWT spring experiment 2018 emphasized the importance of getting NUCAPS data with a latency of less than an hour for forecasting use. The combined NUCAPS MADIS SBCAPE product is displayed on RealEarth from SSEC in near-real time, along with 5 other combined NUCAPS MADIS products: surface-based CIN, surface-based lifted index, mean-layer CAPE, mean-layer CIN, and meanlayer lifted index (https://realearth.ssec.wisc.edu/). These other parameters are also stability indices computed using SHARPpy and can help in forecasting convective weather. These products, along with the SBCAPE, are located under the tab "JPSS-NUCAPS" under "Products." RealEarth is a visualization tool from University of Wisconsin-Madison-SSEC that updates in near-real time. It provides a user-friendly interface available through any Internet browser or on the SSEC RealEarth mobile application. The NUCAPS + MADIS combined products are derived from subsequent overpasses and are displayed to create a geotiff image over CONUS that updates on RealEarth within seconds of generation. An example of the RealEarth interface is displayed in Fig. A1 during Hurricane Florence, which can be seen making landfall on North Carolina.

\section{REFERENCES}

Blanchard, D. O., 1998: Assessing the vertical distribution of convective available potential energy. Wea. Forecasting, 13, 870-877, https://doi.org/10.1175/1520-0434(1998)013<0870: ATVDOC $>2.0 . \mathrm{CO} ; 2$.

Blumberg, W. G., K. T. Halbert, T. A. Supinie, P. T. Marsh, R. L. Thompson, and J. A. Hart, 2017: SHARPpy: An open source sounding analysis toolkit for the atmospheric sciences. Bull. Amer. Meteor. Soc., 98, 1625-1636, https://doi.org/10.1175/ BAMS-D-15-00309.1. 
Bowlan, M., and K. Calhoun, 2018: GOES-R and JPSS Proving Ground Demonstration at the Hazardous Weather Testbed 2018 Spring Experiment Final Evaluation. GOES-R/ JPSS Proving Ground Demonstrations Documentation, 59 pp., https://www.goes-r.gov/users/docs/pg-activities/ HWT2018_SE_GOESRPG_Final_Report.pdf.

Bunkers, M. J., B. A. Klimowski, and J. W. Zeitler, 2002: The importance of parcel choice and the measure of vertical wind shear in evaluating the convective environment. 21st Conf. on Severe Local Storms, San Antonio, TX, Amer. Meteor. Soc., P8.2, https://ams.confex.com/ams/pdfpapers/47319.pdf.

Cintineo, J. L., M. J. Pavolonis, J. M. Sieglaff, and D. T. Lindsey, 2014: An empirical model for assessing the severe weather potential of developing convection. Wea. Forecasting, 29, 639653, https://doi.org/10.1175/WAF-D-13-00113.1.

Craven, J. P., R. E. Jewell, and H. E. Brooks, 2002: Comparison between observed convective cloud-base heights and lifting condensation level for two different lifted parcels. Wea. Forecasting, 17, 885-890, https://doi.org/10.1175/1520-0434(2002)017<0885: $\mathrm{CBOCCB}>2.0 . \mathrm{CO} ; 2$

De Pondeca, M. S., and Coauthors, 2011: The real-time mesoscale analysis at NOAA's National Centers for Environmental Prediction: Current status and development. Wea. Forecasting, 26, 593-612, https://doi.org/10.1175/WAF-D-10-05037.1.

Dostalek, J. F., D. T. Lindsey, and J. M. Haynes, 2017: Using NUCAPS retrievals to diagnose pre-convective environments over the United States. 21st Conf. on Satellite Meteorology/20th Conf. on Air-Sea Interaction, Madison, WI, Amer. Meteor. Soc., 3.1, https://ams.confex.com/ams/ 21SATMET20ASI/webprogram/Paper297117.html.

- — A. Aambacorta, N. Smith, and C. D. Barnet, 2018: Automated modifications to SNPP NUCAPS soundings using surface data for severe weather analysis. 14th Annual Symp. on New Generation Operational Environmental Satellite Systems, Austin, TX, Amer. Meteor. Soc., 11A.6, https://ams.confex.com/ ams/98Annual/webprogram/Paper333108.html.

Doswell, C. A., III, and E. N. Rasmussen, 1994: The effect of neglecting the virtual temperature correction on CAPE calculations. Wea. Forecasting, 9, 625-629, https://doi.org/10.1175/ 1520-0434(1994)009<0625:TEONTV >2.0.CO;2.

Gambacorta, A., 2013: The NOAA Unique CrIS/ATMS Processing System (NUCAPS): Algorithm Theoretical Basis Documentation, version 1.0. NOAA Center for Weather and Climate Prediction, 78 pp., https://www.ospo.noaa.gov/Products/atmosphere/ soundings/nucaps/docs/NUCAPS_ATBD_20130821.pdf.

Gambacorta, A., and C. D. Barnet, 2013: Methodology and information content of the NOAA NESDIS operational channel selection for the Cross-Track Infrared Sounder (CrIS). IEEE Trans. Geosci. Remote Sens., 51, 3207-3216, https:// doi.org/10.1109/TGRS.2012.2220369.

— and - 2018: Atmospheric soundings from hyperspectral satellite observations. Comprehensive Remote Sensing, S. Liang, Ed., Vol. 7, Elsevier, 64-96.

- , and Coauthors, 2014b: The NOAA operational hyper spectral retrieval algorithm: A cross-comparison among the CrIS, IASI and AIRS processing systems. Proc. Int. TOVS Study Conf., Jeju Island, South Korea, International TOVS Working Group, 8.02, https:/cimss.ssec.wisc.edu/itwg/itsc/itsc19/program/presentations/ 28Mar2014/session_8a/8_02_gambacorta.pdf.

, and Coauthors, 2014a: An experiment using high spectral resolution CrIS measurements for atmospheric trace gases: Carbon monoxide retrieval impact study. IEEE Geosci. Remote Sens. Lett., 11, 1639-1643, https://doi.org/10.1109/LGRS.2014.2303641.
- C. Barnet, and M. Goldberg, 2015: Status of the NOAA Unique CrIS/ATMS Processing System (NUCAPS): Algorithm development and lessons learned from recent field campaigns. Proc. Int. TOVS Study Conf., Lake Geneva, WI, International TOVS Working Group, 4.01, https:// cimss.ssec.wisc.edu/itwg/itsc/itsc20/program/PDFs/29Oct/ session4a/4_01_gambacorta.pdf.

, and Coauthors, 2017: The NOAA Unique Combined Atmospheric Processing System (NUCAPS). Proc. Int. TOVS Study Conf., Darmstadt, Germany, International TOVS Working Group, 11.02, https://cimss.ssec.wisc.edu/itwg/itsc/ itsc21/program/1december/1600_11.02_AGAMBACORTA_ 20171201_ITWG\%20lz_final.pdf.

Gartzke, J., R. Knuteson, G. Przybyl, S. Ackerman, and H. Revercomb, 2017: Comparison of satellite-, model-, and radiosonde-derived convective available potential energy in the Southern Great Plains Region. J. Appl. Meteor. Climatol., 56, 1499-1513, https://doi.org/10.1175/JAMC-D-16-0267.1.

Goff, J. A., and S. Gratch, 1946: Low-pressure properties of water from -160 to 212F. Trans. Amer. Soc. Heat. Vent. Eng., 52, 95-121.

Goldberg, M. D., H. Kilcoyne, H. Cikanek, and A. Mehta, 2013: Joint Polar Satellite System: The United States next generation civilian polar-orbiting environmental satellite system. J. Geophys. Res. Atmos., 118, 13 463-13 475, https://doi.org/ 10.1002/2013JD020389.

Halbert, K. T., W. G. Blumberg, and P. T. Marsh, 2015: SHARPpy: Fueling the Python cult. Fifth Symp. on Advances in Modeling and Analysis Using Python, Phoenix AZ, Amer. Meteor. Soc., 402, https://ams.confex.com/ams/95Annual/webprogram/Manuscript/ Paper270233/sharppy_extended_abstract_draft1.pdf.

Hart, J. A., J. Whistler, R. Lindsay, and M. Kay, 1999: NSHARP, version 3.10. Storm Prediction Center, National Centers for Environmental Prediction, Norman, OK, 33 pp.

Holley, D. M., S. R. Dorling, C. J. Steele, and N. Earl, 2014: A climatology of convective available potential energy in Great Britain. Int. J. Climatol., 34, 3811-3824, https://doi.org/ 10.1002/joc.3976.

Iturbide-Sanchez, F., S. R. S. da Silva, Q. Liu, K. L. Pryor, M. E. Pettey, and N. R. Nalli, 2018: Toward the operational weather forecasting application of atmospheric stability products derived from NUCAPS CrIS/ATMS soundings. IEEE Trans. Geosci. Remote Sens., 56, 4522-4545, https://doi.org/10.1109/ TGRS.2018.2824829.

Johns, R. H., and C. A. Doswell, 1992: Severe local storms forecasting. Wea. Forecasting, 7, 588-612, https://doi.org/10.1175/ 1520-0434(1992)007<0588:SLSF $>2.0$. CO;2.

Lowe, P. R., 1977: An approximating polynomial for the computation of saturation vapor pressure. J. Appl. Meteor., 16, 100-103, https://doi.org/10.1175/1520-0450(1977)016<0100: AAPFTC $>2.0 . \mathrm{CO} ; 2$.

McNulty, R. P., 1995: Severe and convective weather: A central region forecasting challenge. Wea. Forecasting, 10, 187-202, https:// doi.org/10.1175/1520-0434(1995)010<0187:SACWAC >2.0.CO;2.

Miller, P. A., M. F. Barth, L. A. Benjamin, R. S. Artz, and W. R. Pendergrass, 2005: The Meteorological Assimilation and Data Ingest System (MADIS): Providing value-added observations to the meteorological community. 21st Conf. on Weather Analysis and Forecasting/17th Conf. on Numerical Weather Prediction, Washington, DC, Amer. Meteor. Soc., P1.95, https://ams.confex.com/ ams/WAFNWP34BC/techprogram/paper_98637.htm.

Nalli, N. R., and Coauthors, 2013: Validation of satellite sounder environmental data records: Application to the Cross-track 
Infrared Microwave Sounder Suite. J. Geophys. Res., 118, 13 628-13 643, https://doi.org/10.1002/2013JD020436.

, and Coauthors, 2018: Validation of atmospheric profile retrievals from the SNPP NOAA-Unique Combined Atmospheric Processing System. Part 1: Temperature and moisture. IEEE Trans. Geosci. Remote Sens., 56, 180-190, https:// doi.org/10.1109/TGRS.2017.2744558.

Riemann-Campe, K., K. Fraedrich, and F. Lunkeit, 2009: Global climatology of convective available potential energy (CAPE) and convective inhibition (CIN) in ERA-40 reanalysis. Atmos. Res., 93, 534-545, https://doi.org/10.1016/j.atmosres.2008.09.037.

Rochette, S. M., J. T. Moore, and P. S. Market, 1999: The importance of parcel choice in elevated CAPE computations. Natl. Wea. Dig., 23 (4), 20-32.

Rogers, E., and Coauthors, 2009: The NCEP North American mesoscale modeling system: Recent changes and future plans. 23rd Conference on Weather Analysis and Forecasting/19th Conference on Numerical Weather Prediction, Amer. Meteor. Soc., 2A.4, https://ams.confex.com/ams/pdfpapers/154114.pdf.

Rothfusz, L., C. Karstens, and D. Hilderband, 2014: Next-generation severe weather forecasting and communication. Eos, Trans. Amer. Geophys. Union, 95, 325-326, https://doi.org/ 10.1002/2014EO360001.

Smith, W. L., and Coauthors, 2009: Evolution, current capabilities, and future advances in satellite ultra-spectral IR sounding. Atmos. Chem. Phys., 9, 5563-5574, https://doi.org/10.5194/ acp-9-5563-2009.

Sun, B., A. Reale, F. H. Tilley, M. E. Pettey, N. R. Nalli, and C. D. Barnet, 2017: Assessment of NUCAPS S-NPP CrIS/ ATMS sounding products using reference and conventional radiosonde observations. IEEE J. Sel. Top. Appl. Earth Obs. Remote Sens., 10, 2499-2509, https://doi.org/10.1109/ JSTARS.2017.2670504.

Susskind, J., J. M. Blaisdell, L. Iredell, and F. Keita, 2011: Improved temperature sounding and quality control methodology using AIRS/AMSU data: The AIRS Science Team version 5 retrieval algorithm. IEEE Trans. Geosci. Remote Sens., 49, 883-907, https://doi.org/10.1109/TGRS.2010.2070508.

,$- \ldots$, and -2014 : Improved methodology for surface and atmospheric soundings, error estimates, and quality control procedures: The Atmospheric Infrared Sounder Science Team version-6 retrieval algorithm. J. Appl. Remote Sens., 8, 084994-084994, https://doi.org/10.1117/1.JRS.8.084994.

Thompson, R. L., R. Edwards, and J. A. Hart, 2002: Evaluation and interpretation of the supercell composite and significant tornado parameters at the Storm Prediction Center. 21st Conf. on Severe Local Storms, San Antonio, TX, Amer. Meteor. Soc., J3.2, https://ams.confex.com/ams/pdfpapers/46942.pdf.

Tobin, D. C., and Coauthors, 2006: Atmospheric Radiation Measurement site atmospheric state best estimates for Atmospheric Infrared Sounder temperature and water vapor retrieval validation. J. Geophys. Res., 111, D09S14, https:// doi.org/10.1029/2005JD006103.

Wheeler, A., N. Smith, A. Gambacorta, C. Barnet, and M. Goldberg, 2018: Evaluation of NUCAPS products in AWIPS-II: Results from the 2017 HWT. 14th Annual Symp. on New Generation Operational Environmental Satellite Systems, Austin, TX, Amer. Meteor. Soc., 237, https://ams.confex.com/ams/ 98Annual/webprogram/Manuscript/Paper337401/AWheeleretal_AMS2018_NUCAPS_preconvective_HWT_cases.pdf. 